June $2000 \quad$ • NREL/SR-550-28329

\title{
Comparative Analysis of Alternative Means for Removing Noncondensable Gases from Flashed-Steam Geothermal Power Plants
}

\section{April 1999-March 2000}

Martin Vorum, P.E.

Englewood, Colorado

Eugene A. Fritzler, P.E.

Fort Morgan, Colorado

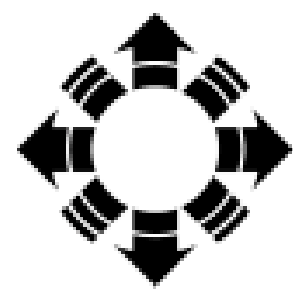

\section{NPEI}

National Renewable Energy Laboratory

1617 Cole Boulevard

Golden, Colorado 80401-3393

NREL is a U.S. Department of Energy Laboratory

Operated by Midwest Research Institute $\bullet$ Battelle $\bullet$ Bechtel

Contract No. DE-AC36-99-G010337 


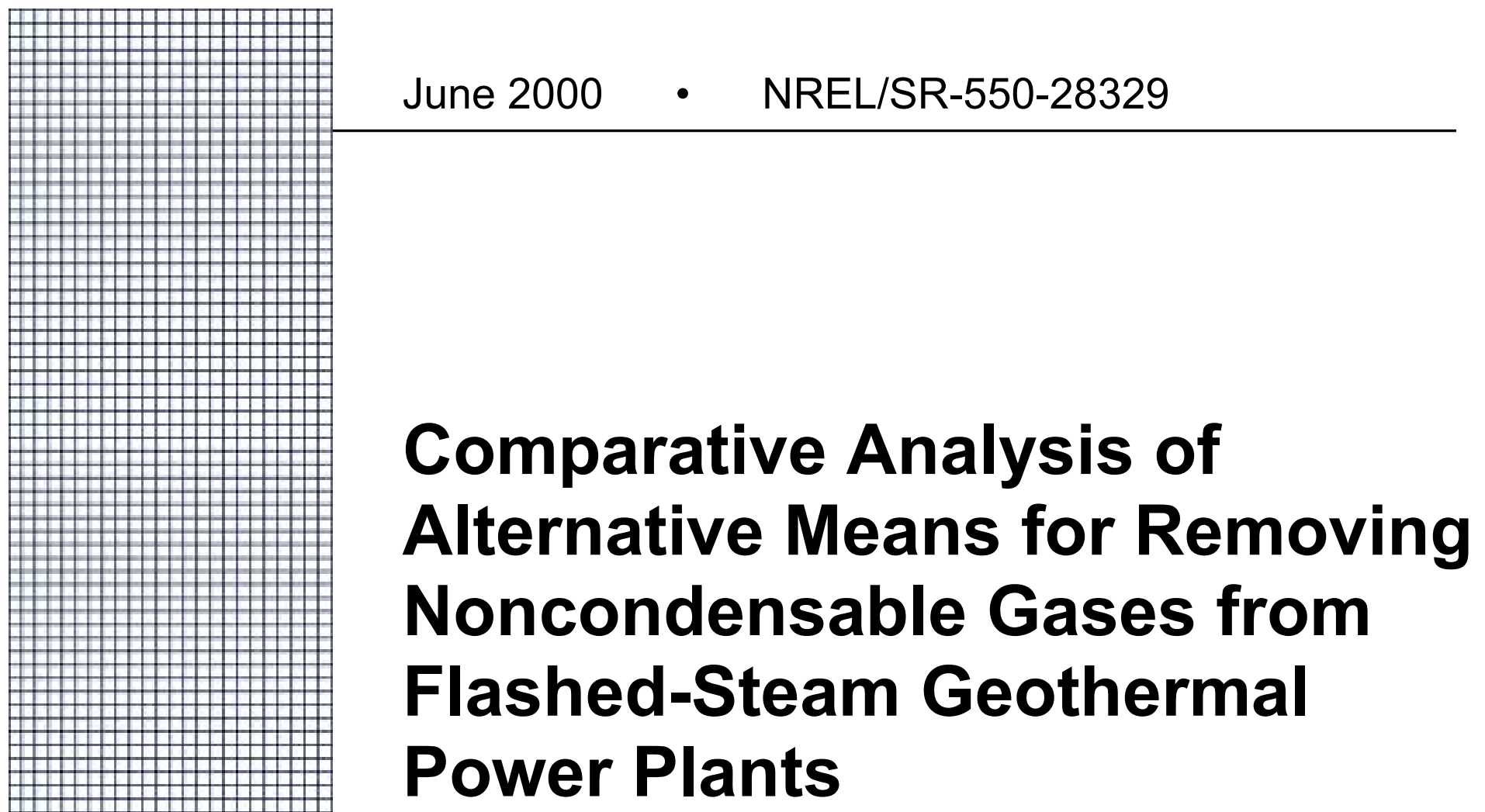

\section{April 1999-March 2000}

Martin Vorum, P.E.

Englewood, Colorado

Eugene A. Fritzler, P.E.

Fort Morgan, Colorado

NREL Technical Monitor: C. Kutscher

Prepared under Subcontract No. AXG-9-29432-01

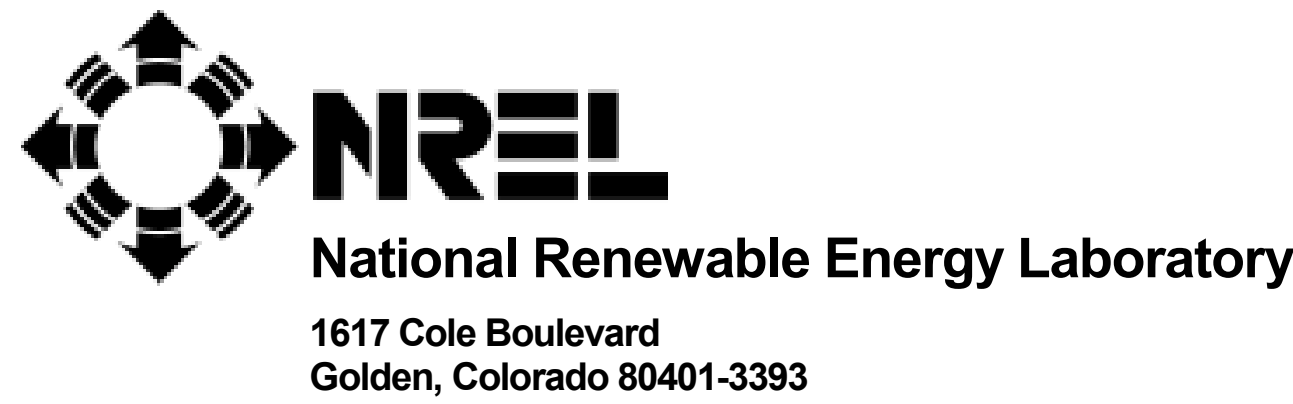

NREL is a U.S. Department of Energy Laboratory

Operated by Midwest Research Institute $\bullet$ Battelle $\bullet$ Bechtel

Contract No. DE-AC36-99-G010337 


\section{NOTICE}

This report was prepared as an account of work sponsored by an agency of the United States government. Neither the United States government nor any agency thereof, nor any of their employees, makes any warranty, express or implied, or assumes any legal liability or responsibility for the accuracy, completeness, or usefulness of any information, apparatus, product, or process disclosed, or represents that its use would not infringe privately owned rights. Reference herein to any specific commercial product, process, or service by trade name, trademark, manufacturer, or otherwise does not necessarily constitute or imply its endorsement, recommendation, or favoring by the United States government or any agency thereof. The views and opinions of authors expressed herein do not necessarily state or reflect those of the United States government or any agency thereof.

Available electronically at http://www.doe.gov/bridge

Available for a processing fee to U.S. Department of Energy

and its contractors, in paper, from:

U.S. Department of Energy

Office of Scientific and Technical Information

P.O. Box 62

Oak Ridge, TN 37831-0062

phone: 865.576.8401

fax: 865.576.5728

email: reports@adonis.osti.gov

Available for sale to the public, in paper, from:

U.S. Department of Commerce

National Technical Information Service

5285 Port Royal Road

Springfield, VA 22161

phone: 800.553.6847

fax: 703.605.6900

email: orders@ntis.fedworld.gov

online ordering: http://www.ntis.gov/ordering.htm

Printed on paper containing at least $50 \%$ wastepaper, including $20 \%$ postconsumer waste 


\section{Table of Contents}

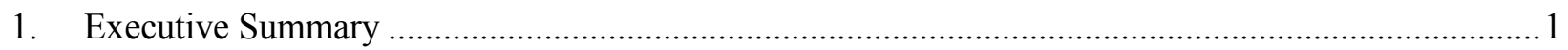

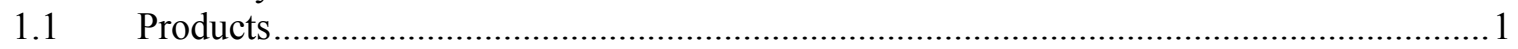

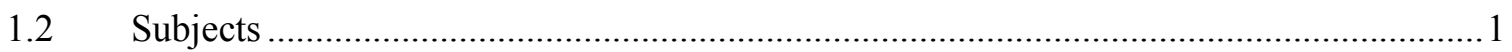

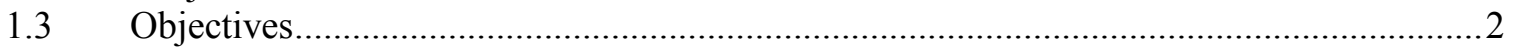

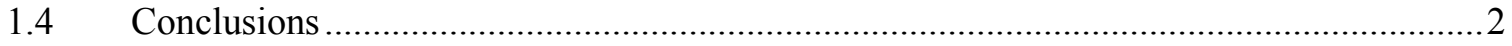

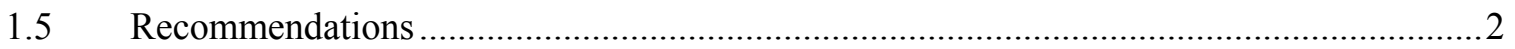

2. Background and Introduction ...........................................................................................

2.1 Issues and Objectives: Effects and Costs of Gases in Geothermal Power Generation ........5

$2.2 \quad$ Project Statement of Work (SOW) ..........................................................................

2.3 Applications to Site-Specific Cases and Other Conditions ..................................................

2.4 Overview of Gas-Removal Technologies .....................................................................

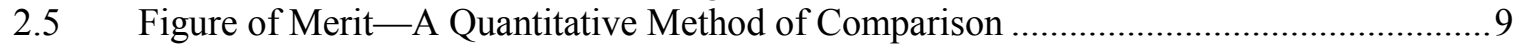

3. Methods of Analysis of Power Processes........................................................................................11

3.1 General Comments on Gas-Removal Process Analysis..................................................11

3.2 Geothermal Power Plant System Definition …………………………………………...11

3.3 Issues Defined: Model Plant Profile, Fluid Flows, Gross Power, Energy Demands .........12

$3.4 \quad$ Integrated System Analysis ........................................................................................ 17

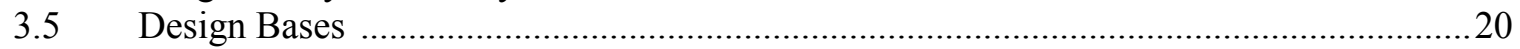

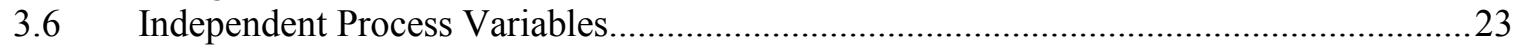

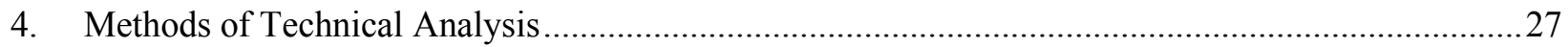

$4.1 \quad$ Technical Figure of Merit .....................................................................................2

4.2 Applications to Site-Specific Conditions ……………………………………………....22

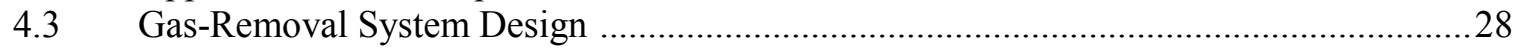

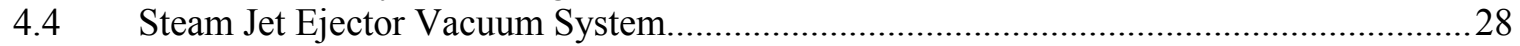

4.5 Three-Stage Turbocompressor Vacuum System ……………………………………...28

4.6 Hybrid Vacuum System ............................................................................................29

$4.7 \quad$ Biphase Eductor Vacuum System ..............................................................................29

4.8 Reboiler Gas-Removal Process .....................................................................................

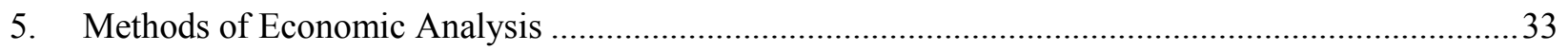

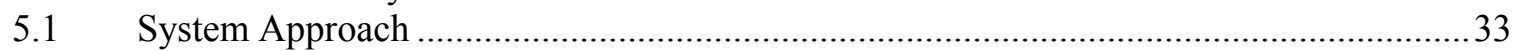

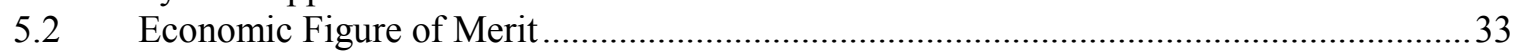

$5.3 \quad$ NPV Financial Parameters ……………………………………………………....... 34

5.4 Cost Data for Specific Gas-Removal Technologies..........................................................34

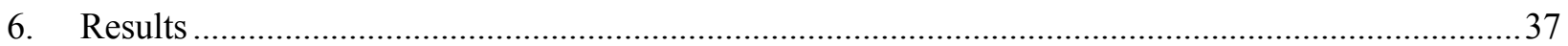

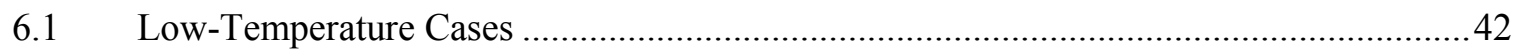

$6.2 \quad$ High-Temperature Cases.....................................................................................4

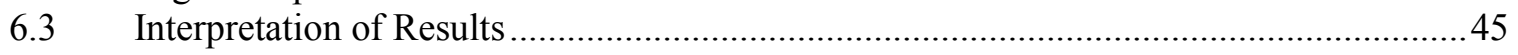

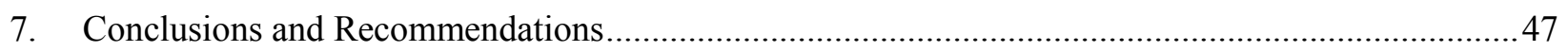

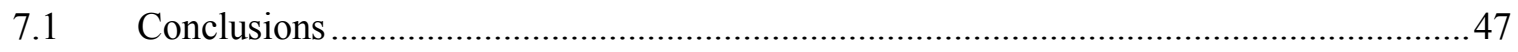

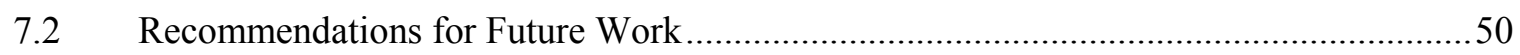

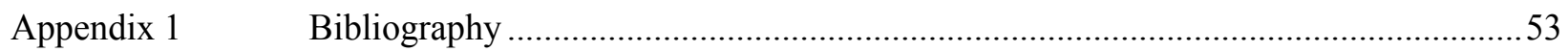

Appendix $2 \quad$ Spreadsheet Description and Printout.....................................................................57 


\section{List of Tables}

Table $1 \quad$ Design Bases and Operating Parameters ................................................................. 18

Table 2 Independent Process Variables...............................................................................2 23

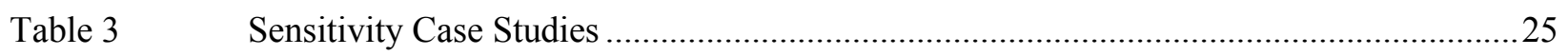

Table $4 \quad$ Equipment Design Parameters, Gas-Removal Components ........................................28

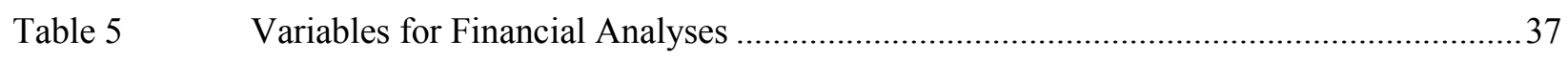

Table $6 \quad$ Recoverable Energy from Flashed Brine versus Flashed Steam..................................43

\section{List of Figures}

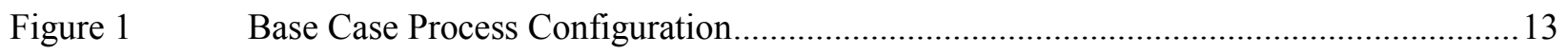

Figure 2 Three-Stage Vacuum System Process Configuration .................................................. 14

Figure 3 Process Configuration with Reboiler for Gas-removal .............................................. 15

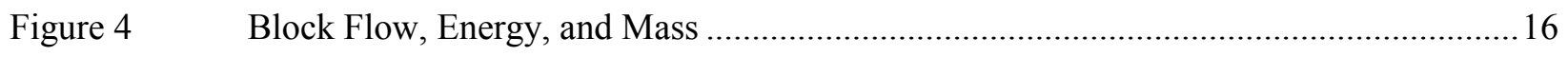

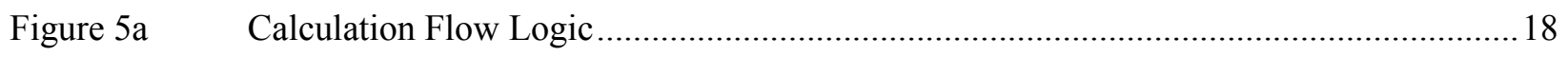

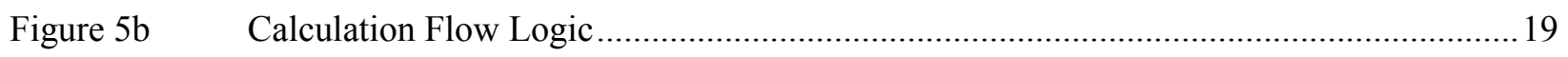

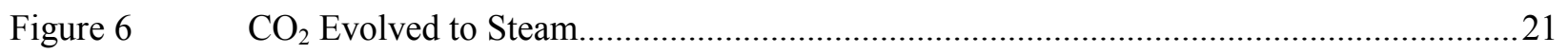

Figure $7 \quad$ Low-Temperature Technical Figure of Merit …....................................................... 38

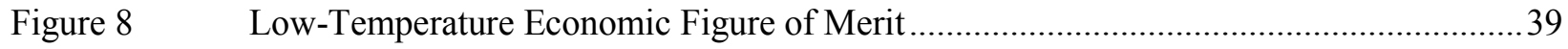

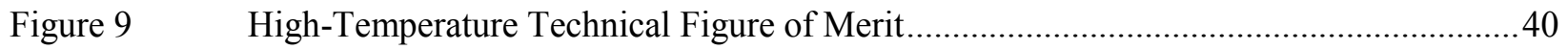

Figure $10 \quad$ High-Temperature Economic Figure of Merit .......................................................... 41 


\section{This Subcontract}

The National Renewable Energy Laboratory (NREL) of the U.S. Department of Energy (DOE) in Golden, Colorado, conducts collaborative research projects such as this study, aimed at improving the efficiency of geothermal power production and addressing issues of environmental concern. This study was conducted for NREL under Subcontract Number AXG-9-29432-01, from April 1999 through March 2000. The principal subcontractor is Mr. Martin Vorum, P.E., Englewood, Colorado, and Mr. Eugene A. Fritzler, P.E., Fort Morgan, Colorado is subcontracted to Mr. Vorum.

\section{Acknowledgments}

The authors have been greatly helped by key developers of the subject technologies whose input was invaluable in constructing accurate models for this study, and by a number of reviewers from the geothermal industry who provided comments that helped us to clarify the report and spreadsheet. Our program manager at NREL, Dr. Charles F. Kutscher, has been particularly helpful in guiding the work, and in helping find very practical solutions to several technical problems. The technical advisory team at NREL, as a whole, was very supportive. Our thanks to all.

\section{Technology Developers and Manufacturers}

\author{
Mr. David Bowlen \\ Dr. Glenn E. Coury \\ Mr. Robert Hagen \\ Mr. Donald Ruck \\ Mr. Jim Hunt \\ Mr. Kenneth Nichols \\ Mr. Jeff Shull \\ Mr. Douglas B. Jung \\ Mr. Alan A. Kornhauser
}

Mr. Dave Parker

Mr. William K. Rouleau
Swenson Process Equipment; Redmond, Washington

Coury \& Associates, Inc.; Wheatridge, Colorado

Graham Manufacturing Co., Inc.; Batavia, New York

Barber Nichols; Arvada, Colorado

Two Phase Engineering \& Research; Santa Rosa, California

Virginia Polytechnic Institute and State University; Blackstone, Virginia

UNECO Treating Systems, Inc.; Bakersfield, California

USFilter, Gas Technology Products; Schaumburg, Illinois 


\section{Reviewers}

Dr. Desikan Bharathan

Dr. Keith Gawlik

Dr. Charles F. Kutscher

Mr. Kevin K. Bloomfield

Mr. Gregory Mines

Mr. Richard G. Campbell

Mr. Kenneth Phair
National Renewable Engineering Laboratory; Golden, Colorado

Idaho National Engineering \& Environmental Laboratory; Idaho Falls, Idaho

The Industrial Company; Pasadena, California

Stone \& Webster Engineering; Englewood, Colorado 


\section{Executive Summary}

\subsection{Products}

This is a final report on a screening study to compare six different methods of removing noncondensable gases from direct-use geothermal steam power plants. This report defines the study methodologies and compares the performance and economics of selected gas-removal systems. Recommendations are presented for follow-up investigations and implementation of some of the technologies discussed in this report.

A companion deliverable product of the study is a spreadsheet that calculates the performance efficiencies and replacement economics for gas-removal technologies. The spreadsheet is a practical tool with which other investigators can also compare the performance and economics of gas-removal systems using:

- Different process conditions

- Different process configurations

- Different technologies than reported for this study

- Different economic assumptions and costs data.

The spreadsheet is a very versatile means of assessing gas-removal systems, including the ability to examine site-specific conditions and practices. As presently programmed, the spreadsheet is used to evaluate system retrofits, but with some alteration it could also rate competing options for new power plant facilities. The data protocols and the analyses give a fair comparison of the net power generation and economics of the gas-removal alternatives.

\subsection{Subjects}

The specific gas-removal methods reported here include five vacuum system configurations that use the conventional approach of evacuating gas/vapor mixtures from the power plant condenser system, and a system for physical separation of steam and gases upstream of the power turbine.

They are:

1. A two-stage system of steam jet ejectors. This is the base case in this study for comparing the alternative systems' performance and economics.

2. A three-stage system using an innovative steam-driven turbocompressor developed for geothermal systems, and featuring very high mechanical efficiencies.

3. A hybrid system using two stages of jet ejectors and a turbocompressor third stage.

4. A hybrid system using two stages of jet ejectors and a liquid ring vacuum pump third stage.

5. A conceptual biphase eductor system powered by flashing spent geothermal brine as the motive fluid, to replace ejector motive steam that has higher value generating electricity.

6. An innovative "reboiler process" that condenses and re-evaporates raw geothermal steam, yielding clean steam as the power plant feed and greatly reducing the vacuum system load.

This study has a nominal focus on flashed-steam applications, but the results apply equally well to both flashed-steam and dry-steam geothermal power plant configurations, as long as the process bases are applied equally. One reviewer suggested that an appropriate focus for this study would have been production systems showing declining resource pressures. That kind of situation also can be accounted for using this study's methods, although the rate of resource pressure decline and its economic implications are beyond the scope of this project. 


\subsection{Objectives}

This study's objectives are to:

- Identify engineering issues and evaluate the mechanical and thermodynamic performance of the gasremoval technologies.

- Determine the costs of the gas-removal methods; and

- Determine the feasibility for each process in terms of its efficiency and relative costs.

These objectives are resolved by applying three sets of analyses:

- Evaluating the design and operating characteristics of systems for generating electrical power using geothermal steam, focusing on the impacts of noncondensable gases.

- Evaluating the design and operating characteristics of processes that remove noncondensable gases from the power systems.

- Evaluating the capital and operating costs to implement the alternatives to the base-case method of removing the noncondensable gases.

\subsection{Conclusions}

Two gas-removal options appear to offer profitable economic potential. The hybrid vacuum system configurations and the reboiler process yield positive net present-value results over wide-ranging gas concentrations. The hybrid options look favorable for both low-temperature and high-temperature resource applications. The reboiler looks profitable for low-temperature resource applications for gas levels above about 20,000 parts per million by volume (ppmv). It might also become economically feasible in high-temperature power plant systems if adopting the reboiler allows offsetting costs to be captured, for example, by eliminating the need for gas abatement systems or by allowing the substitution of lower-cost direct-contact condensers instead of shell-and-tube condensers.

A vacuum system configuration using a three-stage turbocompressor battery may be profitable for lowtemperature resources, but the results also show that a hybrid system is more profitable.

The biphase eductor alternative cannot be recommended for commercialization now. All cases covered in this study showed negative net present values. The cause of the projected losses is a combination of low compression efficiencies and high capital costs.

\subsection{Recommendations}

Geothermal power plant systems with high gas levels and low resource temperatures should be screened for conversions to either a hybrid vacuum gas-removal system or a reboiler system. High-temperature power plants should be screened for conversions to hybrid systems, and if they happen to also require emissions control systems and/or shell-and-tube main condensers, then the reboiler option is worth evaluating, too.

The hybrid turbocompressor system seems to always be more cost effective than a complete conversion to turbocompressors, so the all-turbocompressor vacuum system configuration should probably be dropped from consideration, unless the compressors' unit costs can be shown to be markedly lower than the bases used in this study. 
The biphase eductor technology cannot be profitable unless there is a significant change in the unit efficiency and the costs estimated in this study. The available data on both sets of issues is very limited. If there is interest in researching those improvements, then a progressive screening study should be planned to gather further empirical data with which to better estimate efficiencies and costs, with a clear set of criteria for go/no-go decisions. 


\section{Background and Introduction}

\subsection{Issues and Objectives: Effects and Costs of Gases in Geothermal Power Generation}

Virtually all steam-driven power plants are operated with the power turbines exhausting into condensers at vacuum conditions, to maximize the energy recovered from steam by lowering the temperature of heat rejection. Considering the role of a gas-removal system, optimizing a power process requires balancing the gas-removal system's performance and the resulting marginal revenues versus its capital and operating costs. This report describes the methods and results of calculating gas-removal performance and economics.

Noncondensable gases are natural components of geothermal fluids, and they are a source of considerable capital and operating costs for power plants that generate electricity by the direct use of geothermal steam. The gases must be removed from the process systems to optimize the thermo-dynamic efficiency of the power turbine. This is true whether the geothermal steam feeding a power turbine is derived from flashing brine/steam mixtures from a liquid-dominated geothermal resource, or the wellhead steam is produced as "dry" steam with essentially no entrained brine. This study was specified to apply to flashedsteam geothermal power systems, and the process model defines the envelope for analysis as starting at a brine flash tank receiving saturated liquid or partially flashed brine/steam/gas mixtures from production wells. Within the design scheme for process analyses, power plants that use dry-steam geothermal resources are configured essentially the same as those of flashed-steam systems. Therefore, if geothermal power processes are analyzed at common steam conditions, the results will be equivalent whether the steam originates from a dry-steam geothermal resource or from a flashed-steam production system.

So, while this report uses the context of flashed-steam systems, the data and conclusions are fully applicable to dry-steam systems, as well, except that the biphase eductor option is not feasible for a drysteam resource because it is intended to recover energy from spent geothermal brine.

If there were no gases in the steam driving a power turbine, the turbine exhaust pressure would be fixed by the temperature of the plant cooling water and the efficiency of the main condenser. In simplified terms, the gases in steam interfere with heat transfer in the condenser by forming a film between the bulk steam and the condenser tubes (in indirect condensers) or between the steam and the cooling water droplets (in direct-contact condensers). This "gas-blanketing" effect raises the condenser temperature, which raises the back-pressure on the turbine, which reduces its output. In practice, the gases' effect can only be overcome by evacuating the gases, along with a portion of the steam. Therefore, the noncondensable gases are usually withdrawn by vacuum equipment. A very common type of equipment is the steam jet ejector.

This scenario applies to virtually all steam-driven power plant systems, including fossil-fueled systems, but it is especially costly in geothermal systems because of elevated gas levels that occur naturally in geothermal fluids. Geothermal gas levels are highly variable and site-specific. Values of the order of magnitude of 1 volume percent (10,000 ppmv) are fairly common. Values at or above 100,000 ppmv (10 volume percent) are found at scattered locations around the world, for example, in Turkey, Italy, and the Southeast Asian archipelago.

All methods of removing the gases consume energy in the form of steam or electrical power that would otherwise increase the net salable power plant product. Noncondensable gases and residual steam vapor exit the primary condenser after roughly $75 \%$ to $99+\%$ of the steam has condensed. The mixture is commonly "pumped" up to slightly above atmospheric pressure by multi-stage steam-jet ejectors or by mechanical equipment such as liquid-ring vacuum pumps. Steam-jet ejectors are the most common 
vacuum equipment. They are simple and usually of relatively low installation cost, but are also notoriously inefficient, which is what motivated this study of alternatives.

The practical problems associated with elevated levels of noncondensable gases in geothermal steam power systems are:

- The gases reduce the heat transfer efficiency of the power plant condensers. The primary effect of this is to increase the condenser operating pressure, which reduces turbine power output. As a consequence, overcoming the gas effects requires bigger condensers with greater total heat transfer area and higher costs.

- The gases contribute a partial pressure that adds to the backpressure on the turbine

- If the gas-removal systems (commonly vacuum equipment) underperform, this has the effect of an underdesigned condenser, increasing the power turbine backpressure.

- Noncondensable gases contain lower recoverable specific energy than does steam. The gases dilute the geothermal steam and reduce gross turbine output in the power plant. As a function of its concentration in flashed steam, the contribution of carbon dioxide $\left(\mathrm{CO}_{2}\right)$ to gross turbine power output ranges from less than $0.6 \%$ at $10,000 \mathrm{ppmv}$ to about $10 \%$ at $150,000 \mathrm{ppmv}$.

- However, optimum condenser design and operating conditions are defined, most geothermal steam sources contain higher concentrations (often by orders of magnitude) than those seen in conventional fossil-fueled power plants. This causes proportionally higher capital and operating components for gas-removal in the costs of electricity from geothermal plants.

- Acid gases such as carbon dioxide and hydrogen sulfide are highly water-soluble and contribute to corrosion problems in piping and equipment that contact steam and condensate.

- Conversely, when volatile acid gases evolve from flashing geothermal brine, the $\mathrm{pH}$ of the brine increases. This raises the risk of scale formation in brine piping and equipment, creating a potentially expensive maintenance problem in the process systems that handle both the steam and spent brine, including brine reinjection wells. Geothermal steam also entrains brine mist that causes the buildup of scale in power turbines and in flow systems.

In most geothermal production systems, the predominant noncondensable gas is carbon dioxide, though geothermal resources do produce a variety of other gases, typically in lower concentrations than $\mathrm{CO}_{2}$. Because of its dominant concentrations, the analyses in this study consider only $\mathrm{CO}_{2}$, but the results are broadly applicable to any other gases. Although other gases may be more or less soluble than $\mathrm{CO}_{2}$, by using this gas as the basis for design calculations, the gas-removal models fairly illustrate the comparative power demands of the optional technologies.

On the other hand, if a study were proposed to assess different criteria such as hydrogen sulfide $\left(\mathrm{H}_{2} \mathrm{~S}\right)$ abatement, or the combined effects of multiple gases, or a site-specific gas mixture in which $\mathrm{CO}_{2}$ was not such a majority component, then other modeling assumptions would be appropriate. Any user can analyze such other priorities by changing the basic process data that is the main input to the spreadsheet product of this study. Economic data may also need to be supplemented or revised to suit such case studies. 


\subsection{Project Statement of Work (SOW)}

The main contractual tasks of this project are stated below. Three additional tasks stipulated the production of this report and a technical paper.

Task 1. A literature search and contacts with industry members to define the function of noncondensable gas-removal, and to model the systems currently in use and their potential replacements. This phase developed the bases for the study: i.e., data on realistic commercial plant operating conditions and process configurations; and the means for detailed analysis of steam jet ejectors, mechanical vacuum pumps, the Barber-Nichols turbocompressor, two-phase brine-driven eductors, and the Coury \& Associates reboiler process. This task also defined figures of merit as quantitative analytical tools for comparison of performance and economics.

Task 2. Analysis of the performance and costs of each of the gas-removal methods, based on both engineering fundamentals and field data. Industry members and experts on each of the concepts were consulted further for analytical input and test data.

Task 3. A comparative analysis of the gas-removal methods using an Excel 97 spreadsheet. The spreadsheet defines analytical assumptions and presents the results of process modeling and economic assessments, represented as the figures of merit defined for this study. These incorporate the installation costs of noncondensable gas-removal options, their respective parasitic power costs (as the lost-revenue value of direct steam or electricity used to power the gas-removal systems), and operating and maintenance $(\mathrm{O} \& \mathrm{M})$ costs. The analyses are based on three primary independent variables: the temperature and quality of geothermal fluids, and the gas concentration of the flashed geothermal steam applied to power generation.

\subsection{Applications to Site-Specific Cases and Other Conditions}

This report and the complementary spreadsheet give a preliminary analysis of prominent optional gasremoval subjects. The spreadsheet, in particular, was designed to support others who want to analyze a wide variety of other geothermal power plant scenarios in order to decide if options for gas-removal system retrofits warrant detailed design and economic studies.

The test values (temperature, pressure, quality, and gas concentrations) used in this study are not from any particular geothermal power plant system. They were chosen to bracket a practical range of resource temperatures for flashed-steam plants, and to give a view of the trend of results for a wide range of gas concentrations. From those results, the reader can interpolate to other gas concentrations in the range reported herein. One could also interpolate between the results of high- and low-temperature cases, but with only two temperature data points at each gas level, that involves more uncertainty about the outcome.

However, the spreadsheet can address almost unlimited changes in case details. The process data that define power plant operating profiles can easily be changed. Without changing the process data used in this study, one can change the cost data and assumptions, or vary the economic parameters. For example, as a step toward retrofit assessments, it would be logical to run site-specific data on temperatures, gas concentrations, local economics, company-specific financial parameters, or O\&M costs to refine the evaluations of gas-removal options. 


\subsection{Overview of Gas-Removal Technologies}

Here is a summary of gas-removal system configurations that were considered.

- Two of the vacuum configurations being evaluated are standard methods used in the geothermal power industry. Vacuums are commonly drawn using multiple stages of steam-jet ejectors, and a scheme using two stages of ejectors is the base-case model for this study.

- Some vacuum systems consist of a hybrid scheme using ejectors staged ahead of mechanical pumps. Two configurations of hybrid system were considered in this study. A small, commercial-scale hybrid system has been tested in recent long-term operation at The Geysers geothermal field in California, USA, using a newly developed turbocompressor as a third vacuum stage. The turbocompressor technology has been proven in other applications, but it has seen limited use in geothermal systems. The turbine of these units uses the geothermal steam to power its integral centrifugal compressor. Another hybrid configuration employs a third-stage, liquid-ring vacuum pump powered by an electric motor.

- Two of the alternative vacuum configurations are innovative approaches to replace or reduce the dependence on steam-jet ejectors. They are innovative in that they offer possible improvements in the efficiency of producing a vacuum, thereby reducing the power to run the vacuum system. The trade-offs for these alternatives would be a reduction in parasitic power losses versus higher capital/maintenance costs for the replacement units. One alternative uses a three-stage system, all turbocompressors of the kind applied in the conceptual hybrid system. The benefit of the three-stage turbocompressor system is the compound effect of much higher stage efficiencies.

The other alternative case is a concept to replace vacuum power produced by steam-jet ejectors with power from a three-stage system of eductors (an ejector to handle liquid) that uses flashing, spent geothermal brine as the motive fluid. This scheme is intended to capture residual energy from the spent brine leaving the main flash tank, rather than discard that energy to the brine reinjection system.

- The fifth alternative to the base-case model is called the reboiler process. It uses an innovative, fundamentally different approach to improve geothermal steam power generation by separating gases from the bulk steam phase at line pressure upstream of the power train. The reboiler greatly reduces the gas flow to the turbine and condenser/vacuum system, which, in turn, reduces the size and workload of the vacuum system, thereby cutting parasitic power losses. For new plants, that would also translate into savings by avoiding most of the costs of large vacuum equipment. As above, the trade-off for this alternative compared to steam jet ejectors would be reduced parasitic power losses versus higher capital and maintenance costs.

The reboiler uses a proven, conventional vertical evaporator to both condense and re-evaporate the geothermal steam in one unit, passing a much cleaner steam phase to the power train. The reboiler can be either a non-contact (shell-and-tube) or direct-contact unit; this study evaluates the non-contact device. The reboiler's efficiency is defined by two operating features: It discards a high-pressure vent stream that retains most of the noncondensable gases at much increased concentrations, with a variable fraction of the original geothermal steam. It also degrades the clean steam to a lower pressure before feeding the power turbine. The loss of the vent stream and the steam degradation are the major parasitic energy penalties for the reboiler process.

Depending on local needs and regulations, the reboiler vent stream might be discharged to atmosphere, either directly or after being processed through an emissions control system. 
There is also another process option facilitated by diverting the noncondensable gases to the reboiler vent stream at elevated pressure: The vent stream could be injected underground to avoid the need for abatement processing of that stream. This could represent savings approaching the cost of the reboiler system. Reinjection can be applied to the standalone vent gas stream or by recombining the gases with spent brine as it is injected. This option has been practiced both successfully and unsuccessfully. The issues for gas reinjection require careful economic and hydrogeologic analyses.

In addition, to control the abatement of certain noncondensable gases such as $\mathrm{H}_{2} \mathrm{~S}$, some geothermal power plants have had to use indirect (shell-and-tube) condensers, which are typically much more costly than direct-contact condensers. That added cost might also be avoided using a reboiler technology to separate the produced geothermal gases, and the savings in the condensers would offset a substantial fraction of the reboiler costs.

As these few examples illustrate, the potential combination of offsetting costs and benefits of the reboiler should be reviewed comprehensively.

\subsection{Figure of Merit-A Quantitative Method of Comparison}

A figure of merit is a tool to assess and compare the values of things, processes, methods, etc., using a common basis. This study uses separate, customized technical and economic figures of merit to quantify the power dedicated to gas-removal, and to approximate the recovery of the costs of the gas-removal alternatives.

This study needed the thermodynamic methods applied to complex power system design analyses, and it also had to set the integrated power system bases in a way that focuses on the performance of the gasremoval subsystems. In the technical analyses, the gas-removal subsystems are treated as being interchangeable within an otherwise uniform plant configuration. The technical process comparisons are based on common plant conditions and common plant operating parameters. This puts the performance of the gas-removal subsystems on strictly equal grounds, so that they can be rated by how much they contribute to or take from the overall power plant production.

The technical figure of merit is the ratio of the net power output of two process schemes after deducting the power needed for gas-removal - in all cases in this study, one of the process schemes in the figure of merit is the base-case, two-stage ejector system. The analysis of noncondensable gas-removal methods looks at just the parasitic power demand to run those subsystems as a portion of the fixed generating capacity. All other power plant functions are defined as being constant and equal.

The economic figure of merit evaluates a net present value for converting from steam-jet ejectors to each alternative gas-removal system. This financial analysis ranks the choices by the present value of their future profits or losses. The approach uses estimated costs of construction and operation, and assigns a revenue stream for gas-removal based on the energy saved compared to the base case. The model segregates the costs and revenues of gas-removal from those of the overall power plant. This method probably does not meet the detailed assessments of corporate accounting practices, but it is flexible because of the number of financial variables available to the user. It provides a practical illustration and does a good preliminary job of ranking the economics of gas-removal.

One question that has to be answered outside the scope of this study is whether cost savings projected by these analyses can actually be captured in retrofitting real-world plants. The energy savings of a replacement gas-removal system would be nominally available if the calculated improvements in gasremoval efficiency were real. That could be verified analytically in most cases. However, for any candidate retrofit case that looks favorable on paper, if the existing turbine/generator set or primary 
condenser were not capable of actually using the "saved" steam to generate supplemental electricity, the value of the saved steamed would have to be allocated differently to justify a retrofit project. For example, the rates of steam and brine flows from production wells could be cut back while maintaining the pre-existing net power plant output, potentially prolonging geothermal resource life. That scenario requires a different economic analysis than the one used in this study. 


\section{Methods of Analysis of Power Processes}

\subsection{General Comments on Gas-Removal Process Analysis}

This chapter describes the process configurations, the design bases, and the mass/energy balance methods used to analyze the performance and economics of geothermal power plants. The configuration for power plant systems was planned in order to apply common analyses for all noncondensable gas-removal alternatives. All of the process modeling in this study is based on removing noncondensable gases with some combination of vacuum equipment evacuating the power turbine exhaust vapors. It is relatively simple to analyze such flow schemes on comparable bases while accommodating minor changes in the gas-removal system details. The reboiler process is obviously different in its basic function of gasremoval, but it is still a relatively straightforward matter to analyze the reboiler system configuration in a way that is thermodynamically and economically fully compatible with the systems that rely only on vacuum gas-removal.

The vacuum gas-removal systems rely on converting steam energy to mechanical power to transport the noncondensable gases. The thermodynamic cost of gas-removal by vacuum systems, alone, is accounted for as this dedicated power loss.

The reboiler segregates most of the noncondensable gases by a condensation/re-evaporation step instead of a mechanical compression step. This takes advantage of the differences in chemical potentials of the gases and steam relative to the steam condensate. The reboiler discards the concentrated noncondensable gases and a fraction of the incoming flashed steam as a vent stream; it also passes the majority of the incoming steam to the power turbine with greatly reduced gas loads, but in a degraded condition of lower temperature. An integrated power plant with a reboiler also uses a much-reduced share of its steam energy for vacuum operation. Therefore, the thermodynamic cost of gas-removal by a reboiler is the sum of the loss of steam energy in the vent stream, plus the adiabatic thermal degradation of the turbine feed steam, plus the conventional but smaller vacuum system power demand.

By accounting for these factors in the assumptions, configurations, and analyses of this study, the resultant gas-removal system comparisons are all on a solid basis.

\subsection{Geothermal Power Plant System Definition}

The configuration of flashed-steam geothermal power systems is well established. Figure 1 shows the process flow scheme for the base-case system in this study. The base-case vacuum system is a two-stage steam-jet ejector battery. Figure 2 illustrates the vacuum system in a three-stage configuration, and Figure 3 shows the process with the reboiler inserted after the brine flash step.

For all design cases, this study uses a single power turbine, with straight-through flow of flashed steam and a multi-stage vacuum train downstream of the primary condenser. In the primary condenser, the exit vapor stream is typically reduced to roughly equal-mass flows of steam and gas, so that the vacuum duty addresses the noncondensable gases and a fraction of the incoming steam vapor. There are condensers after each stage of vacuum compression that progressively condense more main exhaust steam and steam used to power the vacuum drivers, in order to minimize the vapor rates and total vacuum horsepower.

The flow schemes in Figures 1, 2, and 3 give a common basis for all of the noncondensable gas-removal approaches. Analyzing the power plant and gas-removal systems' performance follows stepwise calculations of conditions along the path of the flowsheet, converging on the values of mass flow rates, equilibrium phase distributions of chemical components, and energy flux at each unit operation. The equilibrium phase compositions and energy properties were calculated using contemporary steam/water 
properties correlations recommended by the American Society of Mechanical Engineers. Equilibrium gas partitioning values were calculated using distribution coefficients from a recent NREL report by Bharathan, et al. (1996). The gas partition calculations account only for gas solubility in water, but not for the hydration and ionic dissociation of the gas in water.

There are two common blocks designated in the process flowsheets in order to show the logical grouping of related process equipment items. In the upper left section of Figures 1 and 2, a common block encompasses the brine flash separator, power turbine, and spent-brine reinjection system. This is consistent for the five technologies that rely on vacuum systems to remove noncondensable gases. For the reboiler system, in Figure 3 this common block is altered to insert a reboiler system in the steam line between the brine flash tank and the main power turbine.

All six gas-removal configurations require vacuum gas-removal systems similar to the common block of ejectors and secondary condensers in the lower right section of Figure 1. For any particular gas-removal option, this block can be revised to substitute alternative vacuum equipment for the ejectors. This change to a three-stage system is shown in Figure 2 for the turbocompressor system, which also applies to the biphase eductor system, and hybrid cases. In the reboiler process, the vacuum system configuration uses two stages of steam jet ejectors because of their greatly reduced capacity.

\subsection{Issues Defined: Model Plant Profile, Fluid Flows, Gross Power, Energy Demands}

To illustrate the allocation of steam power and electrical energy, Figure 4 depicts a simplified model geothermal power system, highlighting the flow of vapor, brine, and produced electrical power. This shows that both the mass flow and the energy flow to the gas-removal systems downstream of the primary condenser can be discretely identified, and that all other mass and energy flows can be designated as inplant production or consumption, or as net electricity sold as product. Here are features of the flow scheme and conceptual model for the process:

- The mass flow of flashed steam to the power plant systems is common to all cases, and all design cases receive equal feed steam flowrates. The flashed steam flow rate is calculated to support a gross generation rate of 50 megawatts (MW) of electrical power before discounting any parasitic energy demands for noncondensable gas-removal.

- The base case uses a two-stage steam-jet ejector vacuum system for gas-removal.

- The model treats all energy duties for noncondensable gas-removal (either direct steam or internal electrical power) as deductible loads, and compares these power values for all cases to the base-case ejector requirements for gas-removal.

- The process model assumes that, with one exception below, all other utility systems (i.e., site lighting, space heating, process controls, brine management, and any other secondary power demands except those for gas-removal) represent constant loads independent of the gas-removal functions. These loads are assumed to fall within the nominal 50-MW gross plant capacity, too.

- The exception to the preceding assumption is that power for cooling water circulation pumps and cooling tower fans to support the gas-removal systems is estimated and counted as part of the parasitic power load for respective design cases. 


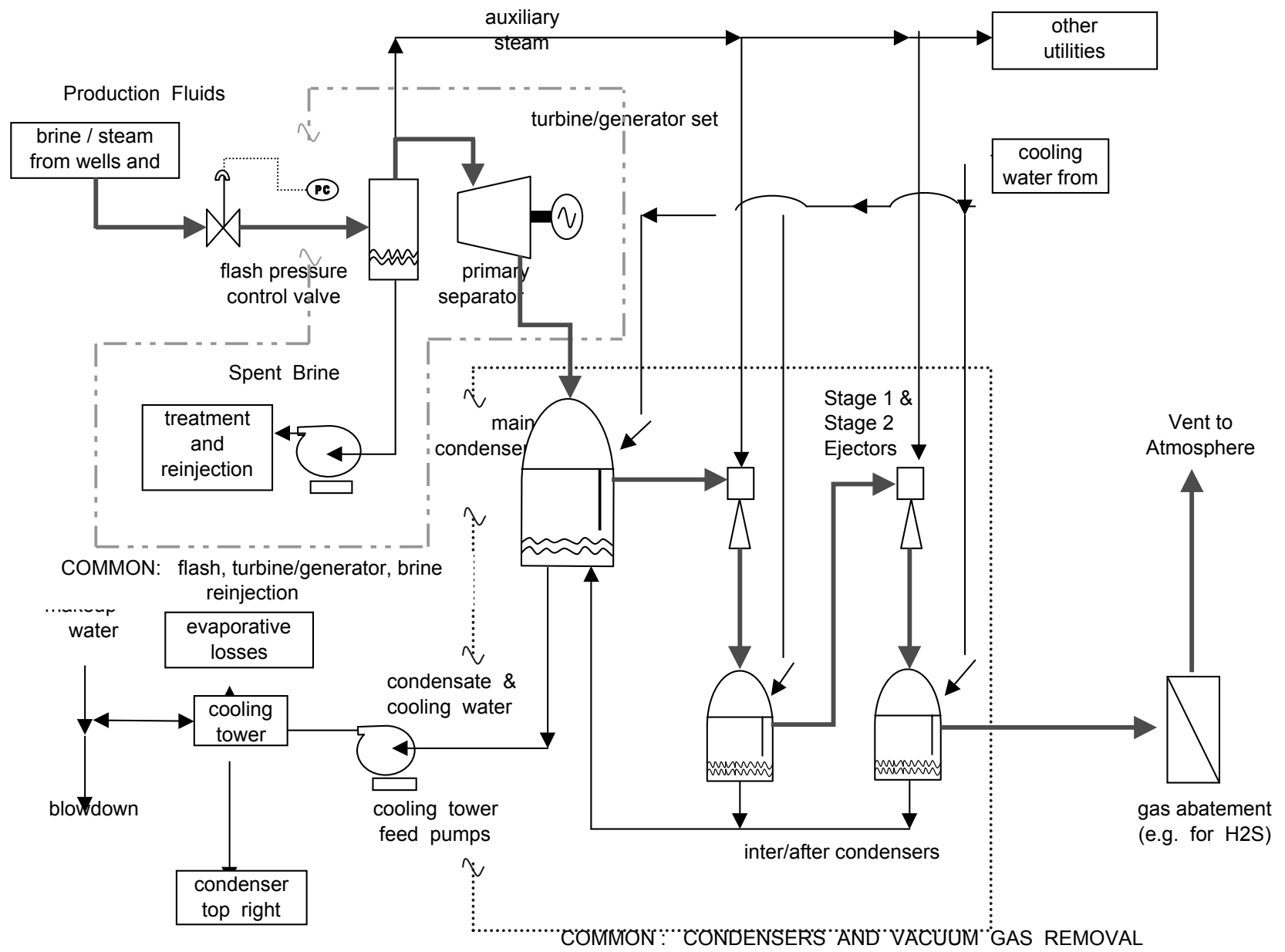

Figure 1 Base-Case Flowsheet

Removal of Noncondensable Gases from Geothermal Power Plant

Vacuum Transport of Gross Turbine Feed Stream through Condensers Using Two-Stage Steam Jet Ejector Battery 


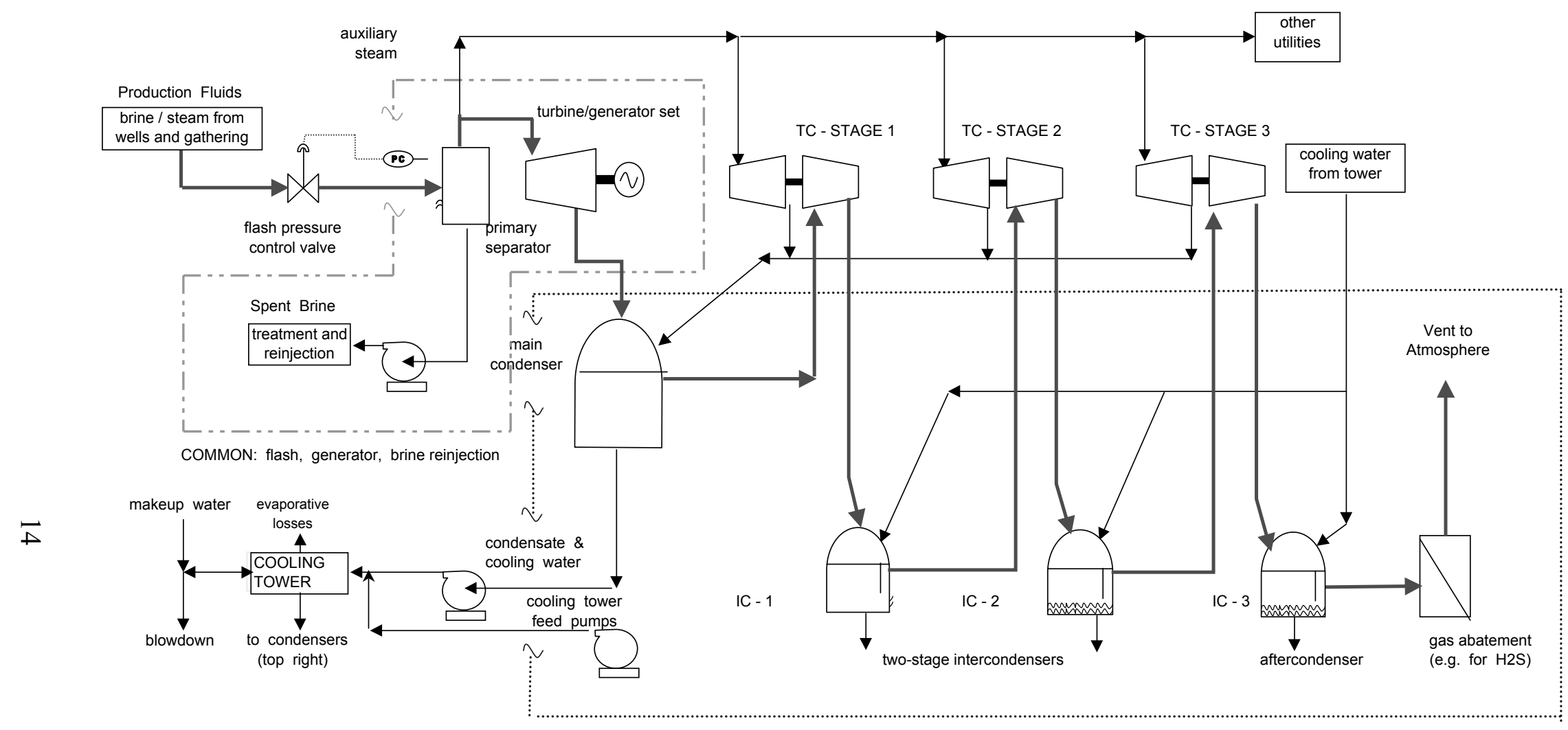

CONDENSERS AND VACUUM GAS REMOVAL

Figure 2 Three-Stage Turbocompressor Flowsheet

Removal of Noncondensable Gases from Geothermal Power Plant

Vacuum Transport of Gross Turbine Feed Stream through Condensers Using Steam-Driven Turbocompressor Battery 


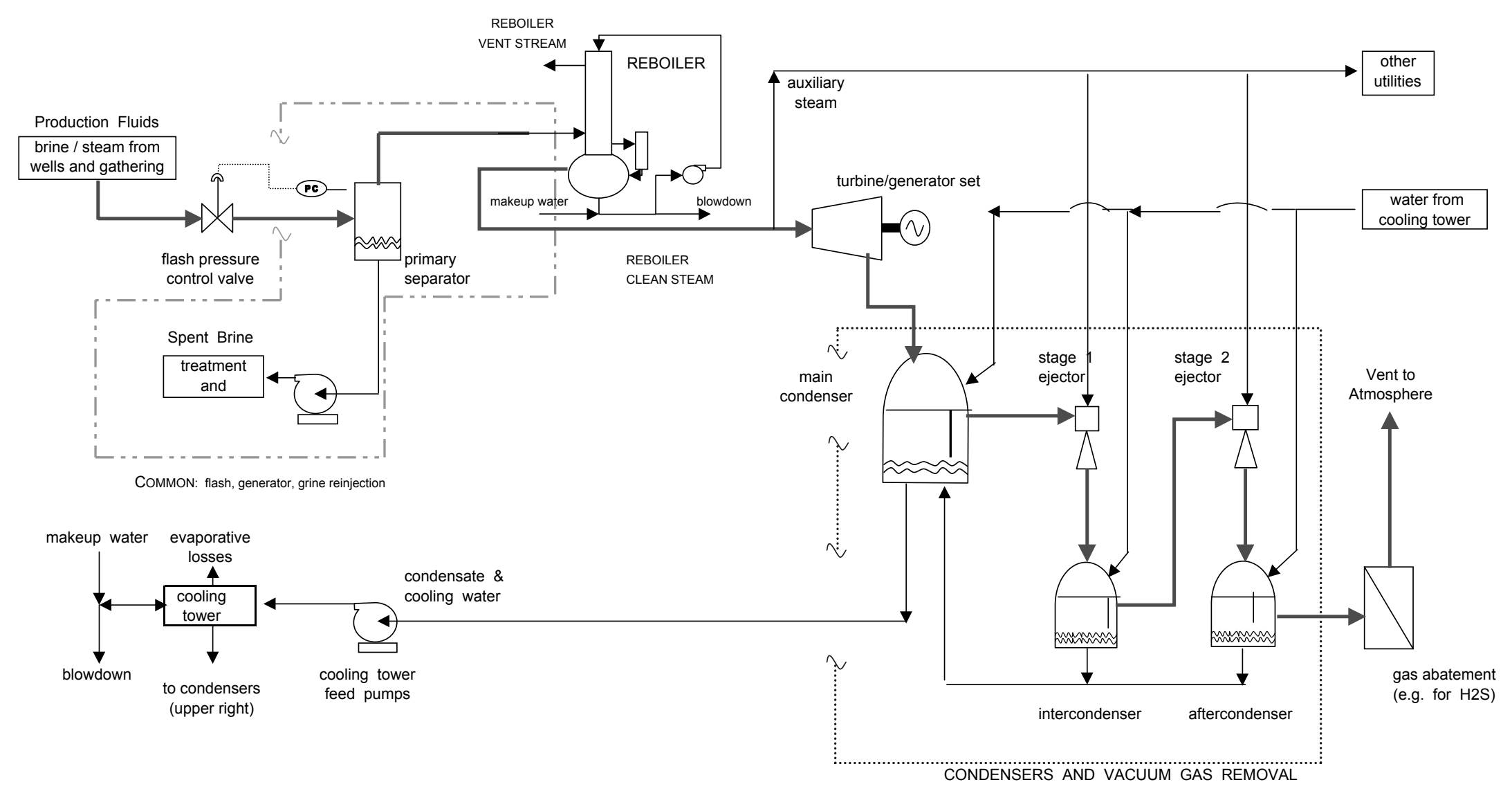

Figure 3 Reboiler Flowsheet

Removal of Noncondensable Gases from Geothermal Power Plant

Vacuum Transport of Gross Turbine Feed Stream through Condensers Using Two-Stage Steam Jet Ejector Battery 
System Boundary for Mass / Energy Balances for

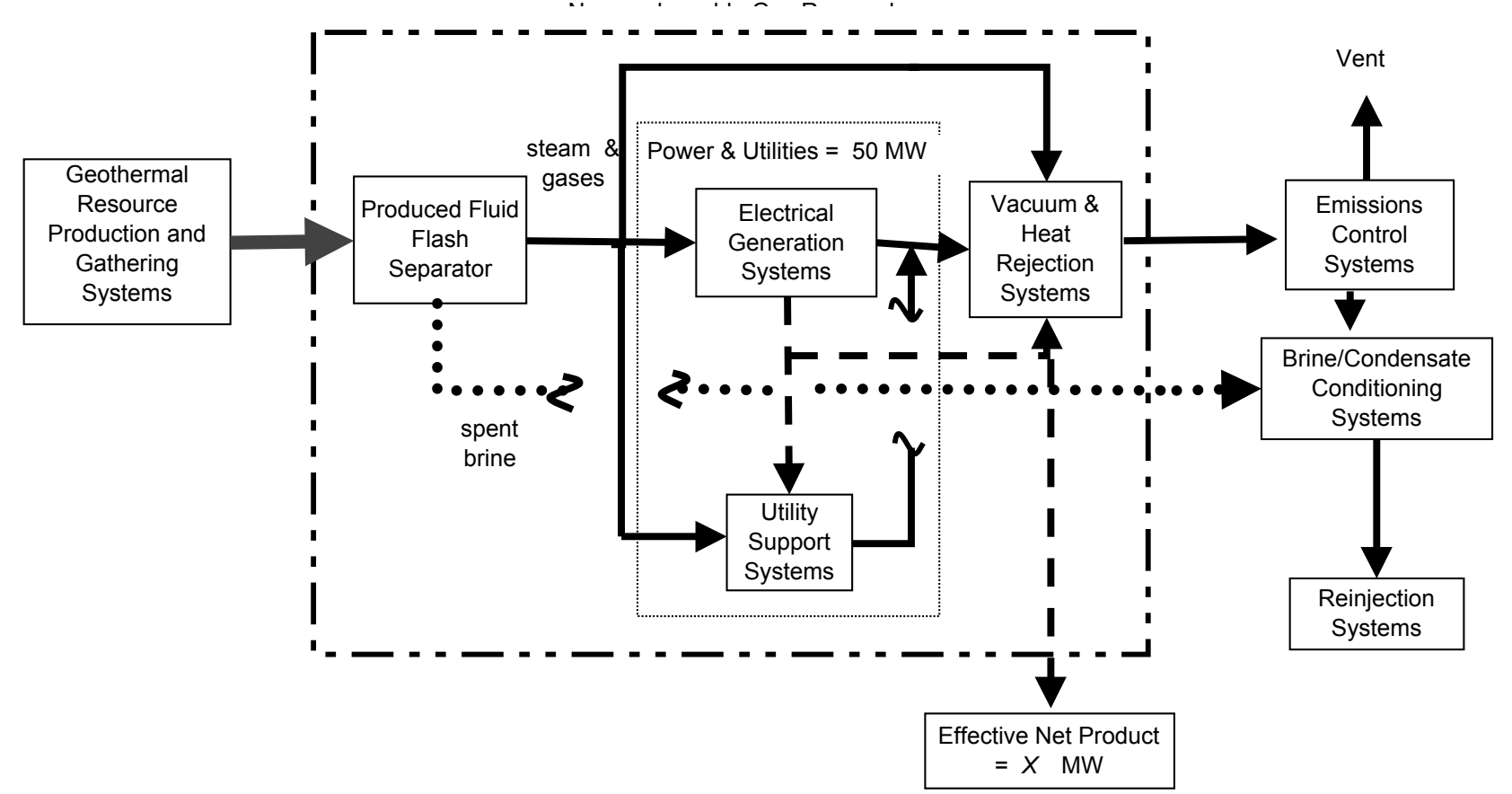

Figure 4 Energy and Mass Flow

For Analysis of Performance and Economics of Noncondensable Gas Removal From Geothermal Electric Generating Systems 
This combination of criteria is the common basis for plant performance, parasitic energy demand, and costs of gas-removal, so that they can be isolated and rated against the 50-MW fixed reference plant capacity. The energy for gas-removal can be quantified as a fraction of gross plant product, and given a dollar value as a potential revenue stream (whether positive or negative). The reader can interpret the gas-removal systems' energy loads to evaluate the need for additional production wells and the impact on resource depletion. These last considerations are critical to the economics of geothermal utility operations, but they are outside the scope of this study.

\subsection{Integrated System Analysis}

Figures $5 \mathrm{a}$ and $5 \mathrm{~b}$ illustrate the logic for computing the mass and energy balances of a geothermal power plant. The general sequence of analyses is listed below.

1. Specify the produced brine conditions at the inlet to the main plant.

2. Estimate a target flash temperature or pressure for the main flash tank.

3. Evaluate vapor/liquid equilibrium conditions and thermodynamic properties at the flashed-fluid conditions. This defines the steam conditions for the turbine feed stream, and gives the gross fluid composition entering the main condenser.

4. For a given case study, local site conditions will be assumed, and cooling water conditions are backcalculated to define the cooling water conditions in the main condenser.

5. For the calculated gross fluid composition and cooling water conditions in the main condenser, a thermo-physical equilibrium is estimated at the condenser hot well.

6. An assumed pressure drop in the condenser is applied, and the thermo-physical equilibrium is backcalculated at the power turbine exhaust.

7. The estimated turbine exhaust condition based on the condenser hot well is compared to the calculated turbine exhaust at its assigned efficiency and inlet conditions. If the two conditions match, go to step 8; if not, return to step 5 and estimate new vapor/liquid conditions in the hot well.

8. The above sequence of steps gives conditions at the inlet and outlet of the turbine, so its power output per pound of feed steam can be calculated. This specific power-recovery value is used to calculate the amount of steam needed to provide a gross 50-MW generator output. This also defines the total flow of brine and steam to the plant, based on the equilibrium calculation in Step 3.

9. The condenser exhaust vapor composition is calculated to determine the net amount of uncondensed steam vapor and noncondensable gases leaving the unit. This is the load gas stream to be compressed by one of the alternative vacuum technology subjects of this study.

10. As per the preceding procedures, the exhaust steam/gas stream is put through calculations of thermophysical equilibria in multiple stages of compression and condensation. The exhaust equilibrium at each condenser stage must be estimated and iteratively calculated, adjusting and repeating as above to close on material and energy balances.

These calculations give the power demand for the vacuum stages. This is the basis for calculating the parasitic power and economics dedicated to the noncondensable gas-removal vacuum systems. 

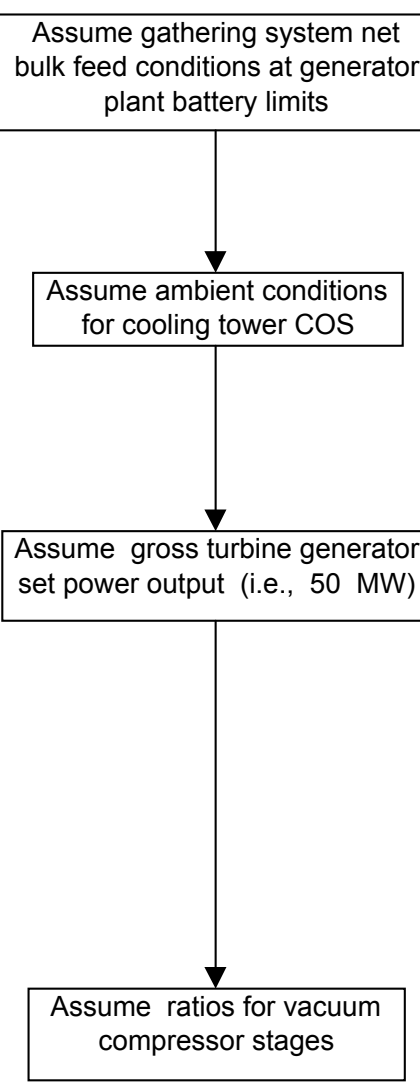

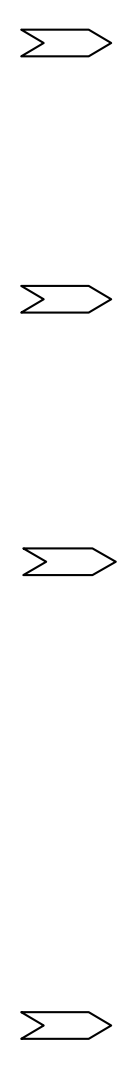

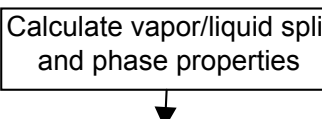

Define turbine

inlet conditions

Calculate condenser conditions

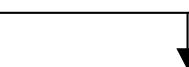

Calculate turbine

outlet conditions

Calculate gross steam, gas flow to meet power output duty

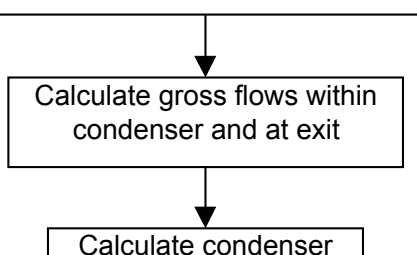

heat duties

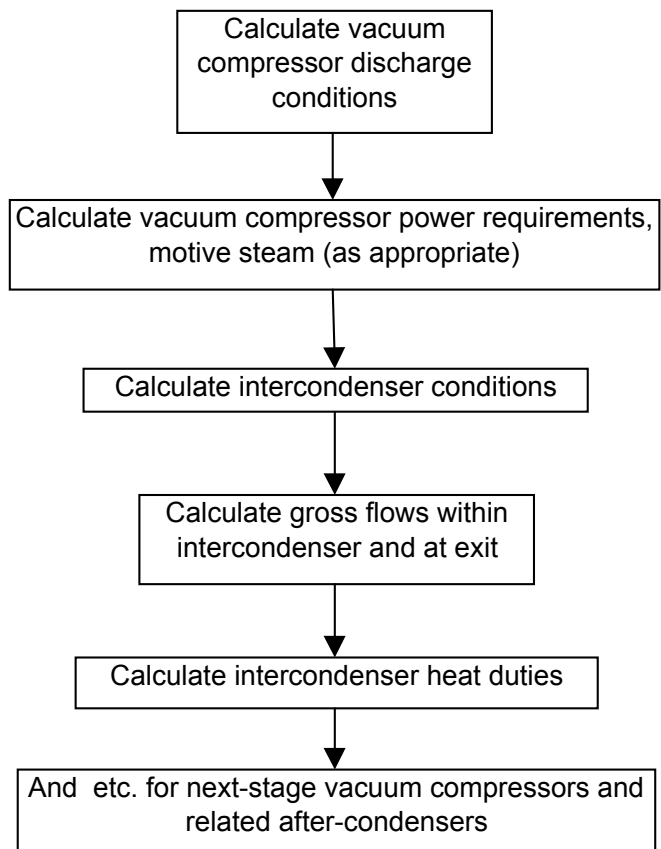

Figure 5a Calculation Logic Schemes

Overall Flowsheet Mass and Energy Balances 


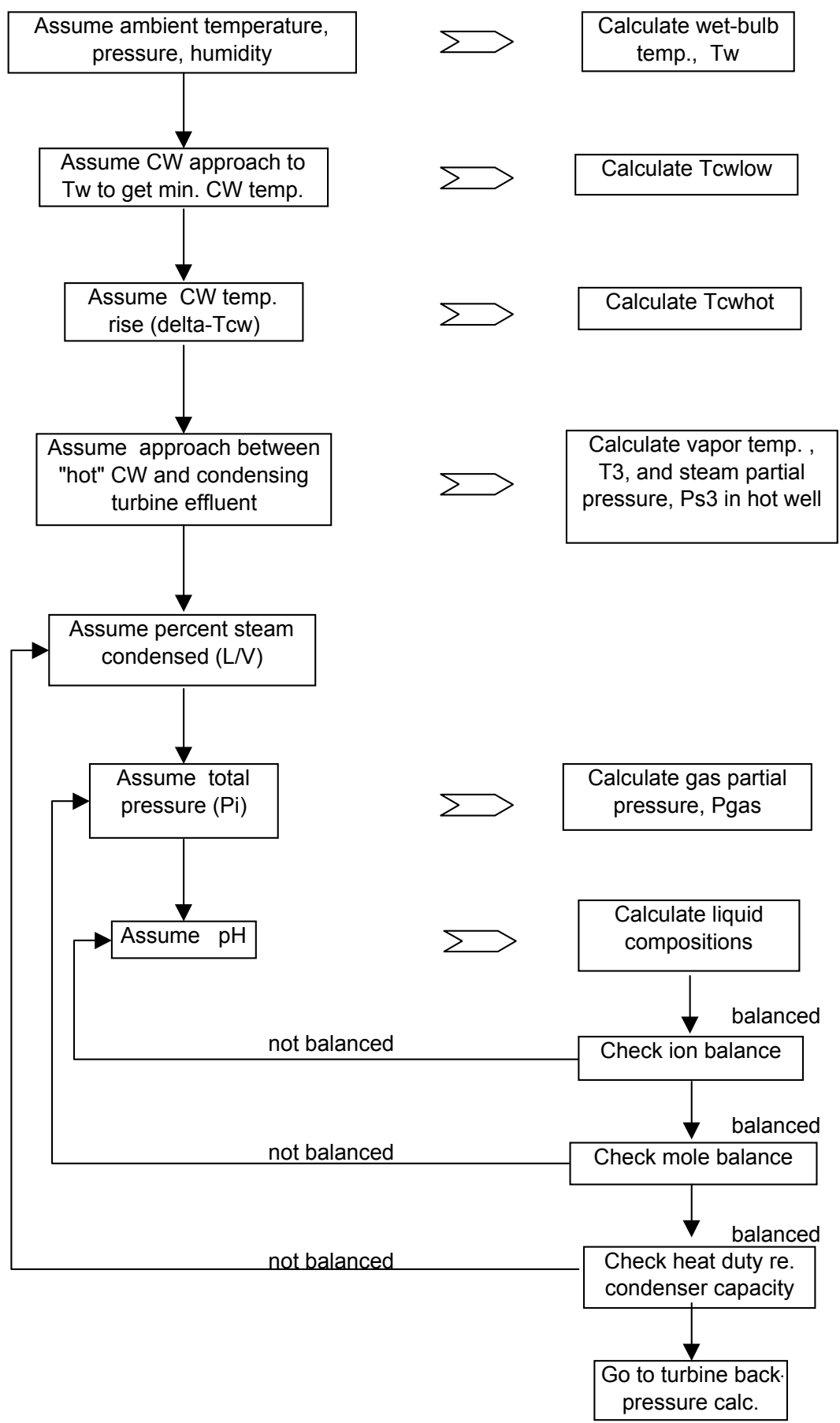

Figure 5b Calculation Logic Schemes

Condenser Temperature, Pressure, Mass Balance 


\subsection{Design Bases}

Table 1 lists the common design bases and operating parameters for the power plant scheme. Descriptions of the variables follow below.

Table 1. Design Bases and Operating Parameters

\begin{tabular}{|c|c|c|}
\hline \multicolumn{2}{|c|}{ Design Bases and Operating Parameters } & Values \\
\hline \multicolumn{2}{|c|}{ Produced fluid flash stages (feed steam to turbine, vacuum drivers, reboiler) } & 1 \\
\hline Flash temperature: & $\begin{array}{l}\text { Relation to delivered wellhead fluid temperature and } \\
\text { turbine outlet temperature }\end{array}$ & Midpoint \\
\hline Turbine configuratior & & Single feed, no pass-outs \\
\hline Turbine efficiency & & $75 \%$ \\
\hline Generator: & $\begin{array}{l}\text { Efficiency } \\
\text { Gross power capacity }\end{array}$ & $\begin{array}{c}95 \% \\
50 \mathrm{MW}\end{array}$ \\
\hline Condenser: & $\begin{array}{l}\text { Direct contact; co-current/counter-current flow paths } \\
\text { Cooling water temperature rise in co-current section } \\
\text { Hot well vapor/liquid temperature approach }\end{array}$ & $\begin{array}{l}25^{\circ} \mathrm{F} \\
3^{\circ} \mathrm{F}\end{array}$ \\
\hline Vacuum system: & $\begin{array}{l}2 \text { or } 3 \text { stages } \\
\text { Barometric condensers after each stage } \\
\text { Discharge pressure }\end{array}$ & $\begin{array}{c}13.8 \text { pounds per square inch } \\
\text { absolute (psia) }\end{array}$ \\
\hline Cooling system: & $\begin{array}{l}\text { Evaporative cooling towers } \\
\text { Wet-bulb temperature } \\
\text { Cooling water approach to wet-bulb temperature }\end{array}$ & $\begin{array}{l}60^{\circ} \mathrm{F} \\
15^{\circ} \mathrm{F}\end{array}$ \\
\hline Site conditions: & $\begin{array}{l}\text { Elevation } \\
\text { Wet-bulb temperature } \\
\text { Ambient pressure }\end{array}$ & $\begin{array}{l}4,200 \text { feet } \\
60^{\circ} \mathrm{F} \\
12.3 \text { psia }\end{array}$ \\
\hline
\end{tabular}

Dual-Stage Versus Single-Stage Flash-For all of the detailed calculations of performance, the produced brine feed to the geothermal power plant is flashed one time to a temperature that is mid-way between the inlet brine temperature and the calculated turbine discharge temperature. This is an approximate way to optimize energy availability from hot brine.

The SOW called for analyzing the geothermal power process for both single- and two-stage flashes of brine. This was evaluated and discussed at two interim project progress meetings. The detailed performance calculations for a dual-flash case were dropped because they do not add practical value, since there is little difference in operating conditions.

By this interpretation, we mean the following. Figure 6 shows the percent of noncondensable gases that enters the steam phase as a function of the degree to which a saturated geothermal brine is flashed to steam. As noted below, the cases of this study showed brine flashes generating about 25 and 38 weight percent steam for plant feed temperatures of $550^{\circ} \mathrm{F}$ and $350^{\circ} \mathrm{F}$, respectively (at inlet to brine flash tank). At those values, Figure 6 shows that about $80 \%$ to $98 \%$ of the noncondensable gas from the feed mixture 
Figure 6

$\mathrm{CO}_{2}$ Evolved to Flashed Steam

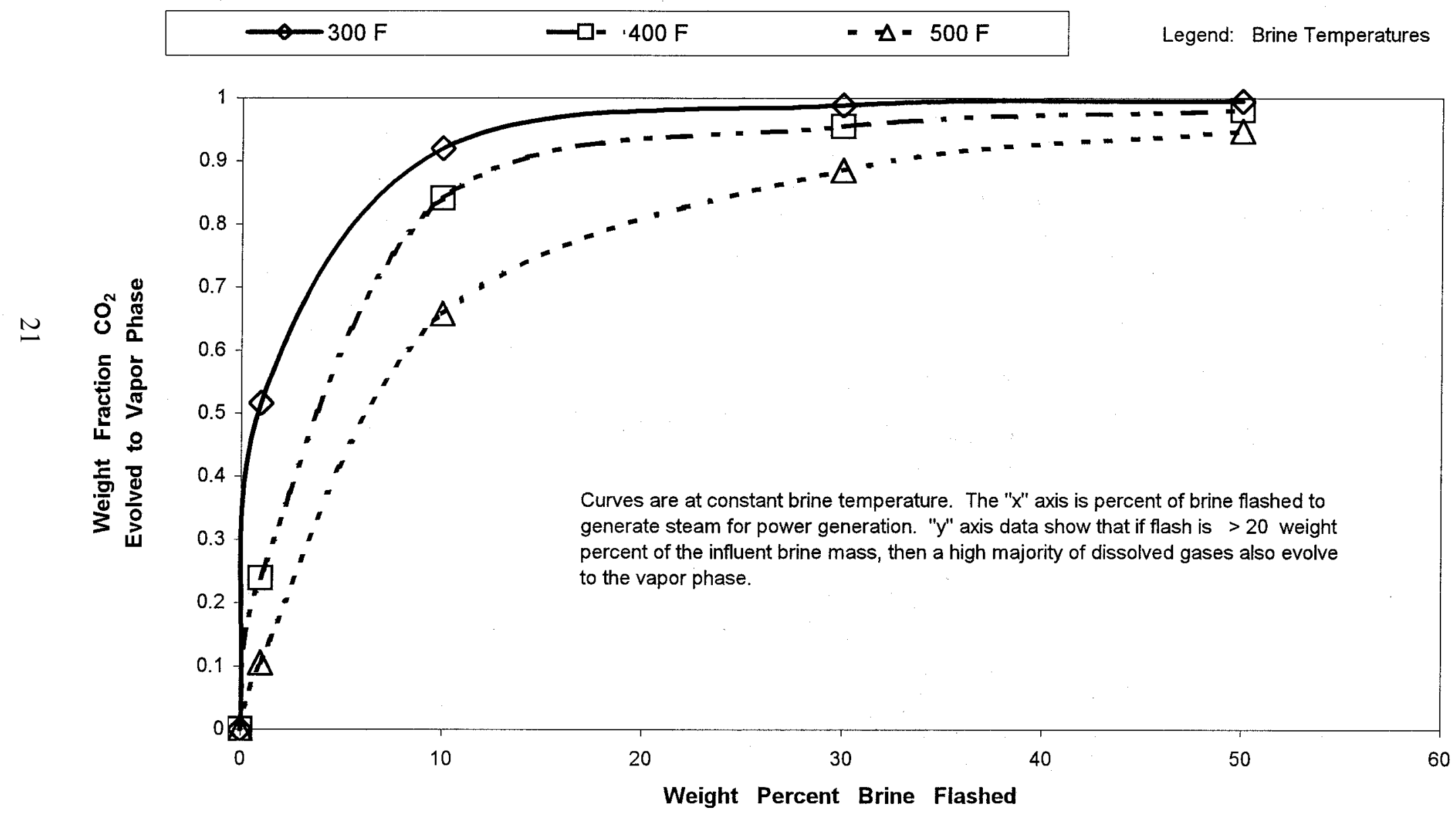


will be released to the vapor phase. Therefore, a second-stage flash would add little to the gas load in the steam flowing to the power turbine and vacuum system. The reason for using multi-stage flashes in power systems is to optimize the thermodynamic cycle for power recovery, but that optimization is not relevant to this study. The single-stage flash produces most of the gas loading that is used to calculate gas-removal effectiveness.

Flash Temperature-The flash temperature is set at the midpoint between the temperatures of the produced fluids and the exhaust of the power turbine. This gives a good first approximation to an optimal thermodynamic power cycle, and it is a common way to approximate a path along a curve such as a steam energy function. This study assigned the temperatures of the produced fluids at $550^{\circ} \mathrm{F}$ and $350^{\circ} \mathrm{F}$, with a quality of $15 \%$ (weight fraction as steam). The midpoint flash temperatures for the brine/steam mixture are $334^{\circ} \mathrm{F}$ and $234^{\circ} \mathrm{F}$, respectively. At these conditions, the flashed steam amounts to about 38 and 25 weight percent, respectively, of the bulk wellhead steam/brine mixture. This is the flashed steam feed to the power plant. The reader can quickly approximate these material balances with a Mollier chart for steam and water, with only slight discrepancies caused by not including the gas effects on the material balances.

Single-Feed Power Turbine with No Pass-Outs-The turbine design for this study uses a single-feed design with no pass-outs of reduced pressure steam for utility applications. To calculate the turbine's power output, it is assumed to have a mechanical efficiency of $75 \%$ relative to an isentropic steam expansion. Gas contributions to the turbine power output are calculated as the enthalpy difference for the gas between the inlet and outlet temperatures. The turbine outlet conditions are dictated by the overwhelming mass of the steam, and the gas enthalpy change is calculated for the temperature changes dictated by the steam properties. As a fraction of the total turbine energy output, the gas enthalpy change contributes about $60 \%$ of its equivalent mass fraction in the stream. While not purely correct, this simplified approach is practical, and the errors in gas contributions to power turbine output would be small but consistent in all cases.

Electrical Generator-The generator is assumed to operate at $95 \%$ overall efficiency in converting the turbine shaft power to electricity.

Direct-Contact Condenser, Co-current/Counter-Current Flow-This study models the condenser as a direct-contact device in which steam and gases from the turbine flow in a co-current pattern with the cooling water into the condenser's hot well. The conditions in the condenser hot well are dictated by an approach temperature difference between the cooling water and the vapor phase; the cooling water is allowed a $25^{\circ} \mathrm{F}$ temperature rise in contact with the turbine exhaust vapors, and the endpoint vapor/water temperature difference in the hot well is assumed to be $3^{\circ} \mathrm{F}$. The residual vapor phase then flows countercurrent to cooling water in an enriching section, and the vapor leaving the condenser is assumed to reach an equal-mass ratio of steam and gas.

These parameters are subject to change in optimizing detailed power plant designs. The process calculations (done off line from the product spreadsheet for this project) account for the gas/steam/condensate equilibria in the direct-contact condensers. Similarly, shell-and-tube condensers could be substituted for the direct-contact type, but the vapor/liquid equilibria would still be needed to estimate flows and power losses for the vacuum system. Shell-and-tube exchangers would also add considerable equipment costs.

Multi-Stage Vacuum Equipment with After-Condensers, Discharging to Atmosphere-For all cases in this study, there is a vacuum system to evacuate gases and residual steam vapor from the condenser system. Each vacuum stage is followed by a contact condenser performing as described above. 
It is assumed that the predominant vacuum configuration in the geothermal power industry uses two stages of steam jet ejectors. Literature on steam-jet ejectors shows that a two-stage system would readily span the compression range for a geothermal power plant condenser train, so that is designated as the base-case design. This study evaluates the biphase eductor, the all-turbocompressor, and hybrid vacuum system cases as three-stage systems. Typically, at any value of single-unit equipment efficiency, adding stages in series improves a system's overall efficiency. Analyzing for three stages illustrates a potential configuration that is adaptable to most vacuum equipment. Since the economics of the changes are also accounted for, this comparison of two-stage and three-stage systems is appropriate to the goal of seeking the potential benefits of alternative gas-removal methods.

Finally, because the reboiler process reduces the gas load in the geothermal power train by an estimated $98 \%$, the vacuum system configuration for the reboiler uses a two-stage ejector because the impact of its low efficiency is much reduced.

The power plant vacuum system is assumed to discharge to atmosphere in this study. Gas treatment may require higher pressures in some site-specific cases, but that would probably make a minimal difference in parasitic power loads, and such optimization is outside the scope of this study. The power loads for the vacuum system are calculated assuming the exhaust pressure design basis is 13.8 psia.

Cooling System and Site Conditions-The cooling system is assumed to be wet cooling towers, and the design parameters for this study are listed in Table 1. Cooling system performance is limited by the ambient conditions - this determines the average and seasonal heat rejection temperature for the thermodynamic plant cycle. Worldwide ambient conditions at geothermal power plants vary widely. For this study, conditions were set for an elevated site with moderate climate conditions; only one set of conditions is examined, so the results do not account for seasonal variations.

\subsection{Independent Process Variables}

Table 2 lists the process conditions that define 48 cases representing six different noncondensable gasremoval technologies. These 48 cases arise from eight combinations of temperature and gas concentration. A selected set of other individual cases was examined to develop approximate indicators of the sensitivity of the system analyses to essential conditions.

Table 2. Independent Process Variables

\begin{tabular}{|l|c|}
\hline \multicolumn{1}{|c|}{ Variables } & Values \\
\hline Produced fluid temperatures (wellhead conditions) & $350^{\circ} \mathrm{F}$ and $550^{\circ} \mathrm{F}$ \\
\hline $\begin{array}{l}\text { Produced fluid quality (weight percent vapor, } \\
\text { wellhead conditions) }\end{array}$ & $15 \%$ \\
\hline $\begin{array}{l}\text { Noncondensable gas levels (in flashed steam } \\
\text { delivered to power turbine) }\end{array}$ & $\begin{array}{c}\text { Parts per million by volume as } \mathrm{CO}_{2}: \text { nominally } 10,000, \\
30,000,50,000,100 \mathrm{~K} / 150 \mathrm{~K}\end{array}$ \\
\hline Dissolved salt content & None \\
\hline
\end{tabular}

Sources of Resource Data-The assumed resource data for the cases in this study are not site-specific. The test cases use conditions that are recognizable as realistic approximations for power systems worldwide. They target practical upper and lower temperature values of producing systems, and the gas concentrations span the majority of foreseeable high loadings. Based on personal communications (Coury, DiPippo 1999), the range of resource conditions is appropriate. The reader can get a feel for the range of geothermal resource conditions from industry literature. Three good sources are DiPippo 
(“Geothermal Energy as a Source of Electricity" 1980); Wahl (“Geothermal Energy Utilization" 1977); and Burgman, et al. ("Next Generation Geothermal Power Plants" 1996).

Three levels of noncondensable gas concentration were picked initially for the test cases to show their impact on the trends of cost and performance relationships for the gas-removal options. The first three sets of case results showed interesting trends, so a fourth gas level was assigned to extend the trends. The limits are high, but:

- The applied range of gas levels starts at $10,000 \mathrm{ppmv}$, which is reasonable for many resources.

- Industry experts have related that there are geothermal resources that do or will produce near the top end of the gas concentration range in this study.

- The study results are practical. They show definitive trends and strong contrasts between technologies, however one judges the suitability of specific design bases and economic assumptions (which can be changed to suit any user's needs).

Produced Fluid Temperature and Pressure-These are the conditions of the bulk vapor/liquid produce fluids at the inlet to the adiabatic flash step. Based on literature and personal communications, the test cases were analyzed at two temperature levels: $350^{\circ} \mathrm{F}$ and $550^{\circ} \mathrm{F}$. The value of $350^{\circ} \mathrm{F}$ was selected because it is slightly above the value of $300^{\circ} \mathrm{F}$ cited as the threshold for economical temperatures for flashed steam power plants. The $550^{\circ} \mathrm{F}$ level is considered a reasonable estimate of upper temperature for most resources. Equilibrium pressures were calculated at the specified temperatures. The spreadsheet lists the fluid pressures and the bulk stream gas concentrations that correspond to the target gas concentrations in the flashed steam.

There are power plants in operation at geothermal resources that have shown declining pressures, and one reviewer suggested evaluating options for such cases. The thermodynamic analyses of this study reflect a snapshot of resource characteristics, so the spreadsheet could be used by any analyst to evaluate the potential benefits of replacing gas-removal systems at both current and projected service conditions. That implies the need to account for the time-dependent behavior of such a system, and to look at the integrated economics of power plant facilities and resource productivity.

Produced Fluid Quality - The condition of the bulk geothermal fluid entering the flash step was defined as having a steam quality (weight percent of fluid as steam vapor) of $15 \%$. At an early stage of the project, additional values of steam quality were considered for evaluation. Information from personal contacts (G. E. Coury, July 1999) indicated that steam qualities in some Southeast Asian resources are in the range of 50 to 60 weight percent steam. However, each additional steam quality value would add 48 test cases. This is not justified, especially since changing the produced fluids' steam quality would have only slight effect on the flashed steam condition, which is the key variable for evaluating gas-removal system performance. It was decided to use only the $15 \%$ steam quality value. The main significance of this value is that it determines how much brine must be produced in order to meet a target value of generated electrical power.

Dissolved Salt Content - Salt concentrations have little bearing on the analyses of this study. They can make a difference of up to several degrees in the boiling points of brines compared to potable water, but that is not a consideration for removing gases from flashed steam. Therefore, salt content was not considered in this study.

Sensitivity Analyses-A selection of the above variables was examined to test the effects of changes to individual parameters in isolated cases. Table 3 lists the combinations of parameters used for sensitivity analyses. The calculation results are tabulated in the spreadsheet, along with a brief discussion of their influence on performance and costs. 
Table 3. Sensitivity Case Studies

\begin{tabular}{|c|c|c|c|c|}
\hline $\begin{array}{c}\text { Produced Fluid } \\
\text { Temperature }\end{array}$ & $\begin{array}{c}\text { Flashed Steam } \\
\text { Noncondensable } \\
\text { Gas Concentration }\end{array}$ & $\begin{array}{c}\text { Steam-Jet } \\
\text { Ejector } \\
\text { Efficiency }\end{array}$ & $\begin{array}{c}\text { Steam-Jet } \\
\text { Ejector } \\
\text { Stages }\end{array}$ & $\begin{array}{c}\text { Wet-Bulb } \\
\text { Temperature }\end{array}$ \\
\hline${ }^{\circ} \mathbf{F}$ & $\mathbf{p p m v}$ & $\%$ & 2 & ${ }^{\circ} \mathbf{F}$ \\
\hline 550 & 50,000 & 15 & 2 & 60 \\
\hline 550 & 30,000 & 23 & & 80 \\
\hline 350 & 10,000 & 15 & 2 & 60 \\
\hline 350 & 10,000 & 23 & 2 & 80 \\
\hline
\end{tabular}




\section{Methods of Technical Analysis}

\subsection{Technical Figure of Merit}

For background, the energy productivity of electrical generating systems is commonly evaluated with the thermodynamic functions named "availability" or "exergy," which define the recoverable energy between inlet and outlet reference conditions for any process configuration. Exergy gives a fundamentally equivalent view with which to compare systems and processes that may operate at different conditions or may need to be engineered differently.

A figure of merit is a tool that can be defined, as needed, as a function to compare multiple systems to show the relationships of their performance. For example, a ratio of the exergy of any test case to that of a reference case would imply that if the test case were thermodynamically more effective, then the ratio of their exergies should be greater than 1.0. The exergy approach was evaluated for this project, and it would be a case of overkill.

A technical figure of merit was defined by starting with an energy balance that focuses on the gasremoval subsystems. To directly compare the power demands of several different gas-removal systems, the technical figure of merit is based on a fixed, uniform power plant design. Gas-removal systems serve as interchangeable modules in a stable plant configuration. Thus, the gas-removal process comparisons are based on common plant conditions and operating parameters. This achieves a fair comparison so that the gas systems can be rated by how much they, alone, contribute to or reduce the net plant electrical generating capacity.

Specifically, the technical figure of merit is the ratio of net electrical output of any test case divided by the net base-case electrical output. Net electrical output is the result of deducting the dedicated parasitic power for gas-removal from the nominal gross plant capacity of $50 \mathrm{MW}$.

In the spreadsheet we define a "net power available" (PA) parameter (in megawatts) as the value of the design basis gross power production (50 megawatts) minus the power required for noncondensable gasremoval. (See the worksheet "OpsDetails" in the spreadsheet sample printout in Appendix 2.) The "residual plant capacity" (RP) represents the net power available as a percent of the $50 \mathrm{MW}$ gross capacity. This gives a measure that ranks the gas-removal processes by showing what fraction of the gross power production remains for sale and to cover other in-plant utility needs after deducting the gasremoval systems' parasitic power demand. Finally, per the definition above, the spreadsheet calculates the technical figure of merit values as the ratios of the respective values of RP for the four alternative gasremoval configurations to the RP value for the base case (two-stage ejector system). A value of technical figure of merit that is greater than 1.0 means that a test case yields more net energy than its corresponding base-case design. If the ratio is less than 1.0, that case is consuming more parasitic power for gasremoval than the base case.

\subsection{Applications to Site-Specific Conditions}

The spreadsheet is designed to let any user run alternative cases. The process input data can easily be replaced to change the temperatures and gas concentrations of the produced fluids. It would make sense to run site-specific data to refine these evaluations of gas-removal options. It may require additional spreadsheet programming efforts to refine the costs for the technologies covered in this report, or to install costs for other gas-removal alternatives, but that is certainly feasible. The spreadsheet was designed to facilitate that sort of extension of its uses. 


\subsection{Gas-Removal System Design}

This section discusses the bases and methods for calculating energy and mass balances in the gas-removal systems. Table 4 lists the controlling parameters for these equipment items.

Table 4. Equipment Design Parameters, Gas-Removal Components

\begin{tabular}{|l|l|c|}
\hline \multicolumn{1}{|c|}{ Equipment Item } & \multicolumn{1}{|c|}{ Design Parameter } & \multicolumn{1}{c|}{$\begin{array}{c}\text { Values } \\
\text { base case (sensitivity cases) }\end{array}$} \\
\hline Steam jet ejector & Energy conversion efficiency & $23 \%(15 \%)$ \\
\hline Turbocompressor & Energy conversion efficiency & $\begin{array}{c}79 \% \text { (compressor wheels) } \\
75 \% \text { (turbine driver wheels) } \\
\text { net machine output } 59.25 \%\end{array}$ \\
\hline Biphase eductor & Energy conversion efficiency & $10 \%(20 \%)$ \\
\hline & $\begin{array}{l}\text { Rejection of noncondensable gases to vent } \\
\text { stream } \\
\text { Steam/gas weight ratio in vent gas } \\
\text { Condensing space pressure drop } \\
\text { Minimum temperature approach }\end{array}$ & $\begin{array}{c}90 / 50 \\
1 \text { psi } \\
1{ }^{\circ} \mathrm{F}\end{array}$ \\
\hline $\begin{array}{l}\text { Reboiler } \\
\text { Liquid Ring Vacuum }\end{array}$ & Energy conversion efficiency & $50 \%$ \\
\hline
\end{tabular}

\subsection{Steam Jet Ejector Vacuum System}

The base-case configuration for this conventional technology uses two stages of steam jet ejectors as the vacuum system to extract gases and steam vapor from the power plant condensers. The ejectors use a portion of the power plant feed steam (including its content of noncondensable gases) as their motive gas.

The thermodynamic analysis of steam-driven vacuum compressors is well established and relatively straightforward. The power calculation requires a balance of enthalpy released by the motive fluid, versus the energy required by the load fluid, in changing from their respective inlet conditions to their common discharge condition. The energy balance is solved isentropically, and then efficiency values specific to the vacuum driver are used to correct the ideal energy value to actual values for the given conditions. The energy balance determines the mass of motive fluid required to drive a given mass of load fluid from the suction pressure to the discharge pressure.

\subsection{Three-Stage Turbocompressor Vacuum System}

This technology uses a relatively new (to geothermal power) and innovative machine that is a steamdriven, centrifugal fluid mover. Using an expander turbine, it recovers power from the same steam that would power the steam jet ejectors of a conventional vacuum system. The power from the expander is transferred to a direct-coupled compressor wheel, which evacuates vapor and gases from the power plant condensers.

The energy analysis for the turbocompressor is identical to the description above for a steam-jet ejector system. The results of the calculation reflect the efficiency used for the turbocompressor. The drive steam and the load gases of the turbocompressor can either mix in the turbocompressor outlet, or the drive steam can report separately to the main condenser. The latter option was used in the model for this study, and the system calculations account for the condensation and recompression of the drive gas. 


\subsection{Hybrid Vacuum System}

A variation on the base-case scheme adds a mechanical vacuum device in series with the two stages of steam jet ejectors. This configuration defines the hybrid gas-removal scheme of this study. The analysis of mass and energy balances is the same as for the steam-jet ejector system. Two sets of hybrid cases evaluated the performance and cost effects of different hybrids: the innovative turbocompressor and a conventional, well-proven liquid ring vacuum pump (LRVP). The turbocompressor is briefly described above. The LRVP is a straight-vaned centrifugal pump into which water is injected, serving as both a coolant and as a seal liquid. The LRVP functions analogously to a positive displacement pump, and offers compression efficiencies considerably higher than those of ejectors, but not as high as the turbocompressor units.

These hybrid configurations offer two benefits: the compounding of added stages to improve overall efficiency and the use of drives with higher efficiencies than the steam jet ejectors in the later stages. The energy analysis method for hybrids again follows that of the base-case system.

\subsection{Biphase Eductor Vacuum System}

According to the biphase eductor vacuum system concept, energy is recovered from geothermal brine downstream of the last brine flash stage that provides steam for electrical generation. That final brine is typically delivered to injection wells, potentially retaining some residual energy that is too degraded to provide steam for power turbines. The conceptual goal of eductors is to capture some of that unused brine energy.

There is no industrial analytical methodology for designing eductors operating with a flashing two-phase drive fluid (Kornhauser, Jung, Coury: personal communications). Limited experimental data exist, all for relatively small-scale tests. One reference article (USDI, Office of Saline Water) shows that predictive correlations adapted from gas (steam) jet ejectors do not consistently predict eductor performance accurately for flashing-liquid drive fluids. That literature calls out the need for extensive testing to develop empirical correlations for nozzle and diffuser performance in this application.

This study calculates the kinetic release of mechanical energy by hot flashing water in the same manner as for steam in an ejector. The power requirement for compression of the load gas stream is also calculated isentropically. The motive fluid flow rate to achieve the compression duty is computed using assumed eductor efficiencies. The USDI reference on eductor tests gives ranges of experimental values for eductor efficiencies using flashing hot water. The report indicated efficiencies scattered broadly from less than $10 \%$ to (optimistically) about $30 \%$. The data were clustered predominantly in the range of $10 \%$ to $20 \%$. What is missing is a correlation of the eductor efficiency versus size and process conditions. For this study, a conservative value of $10 \%$ efficiency is assumed. The discussion of results examines the effect of eductor efficiencies of $20 \%$.

One manufacturer (Graham Corp. 1999) described potential problems with flashing flow in two-phase eductors: the flow regime of the flashing fluids in the mixing zone and/or the diffuser of the eductor may tend to become unstable and make it difficult to maintain steady operation at optimal efficiencies. This suggestion may reflect the significant variability in efficiencies reported in the USDI reference.

The choice of materials for such applications will also be critical to economic operation, and the authors found no data on the erosive effects of high-velocity, two-phase flow on the nozzle and body materials of an eductor. No data were found on the appropriate range of fluid velocities in such applications, either. By analogy from information on flashing fluids in such applications as centrifugal pumps and two-phase 
pipeline flow, it can be expected that the erosive and corrosive effects of geothermal brine in eductor nozzles will be harsh. This study assumes an eductor nozzle velocity of 500 feet per second, which is thought to be an aggressively high velocity for two-phase flow in typical industrial systems. The velocity is the sizing basis for estimating the costs of an eductor package, using the cost of an ejector system of specific capacity as an analogy. Typical steam-jet ejectors operate with gas velocities of up to 5000 feet per second, so the sizing basis for eductors is nominally conservative.

\subsection{Reboiler Gas-Removal Process}

The heart of the reboiler system in this study is a vertical-tube, falling-film evaporator that condenses the raw flashed geothermal steam in the shell-side space, and re-evaporates the clean condensate in the tubeside space. Noncondensable gases remain overwhelmingly in the shell-side vent gas stream. The condensate must be flashed down to a lower pressure in order to establish a temperature driving force for heat transfer across the tube walls.

The thermodynamic cost of the reboiler on power plant productivity is represented by the sum of three factors. The loss of steam that is discarded in the reboiler vent stream is analogous to diverting steam to the parasitic use as drive gas for a large vacuum system. A power plant using a reboiler will still see a demand for steam or electricity to drive a smaller main vacuum system. Finally, the loss in energy via the reboiler's pressure drop cuts into the available power of the steam.

There are two keys to analyzing the reboiler performance. One goal is to determine the temperature profiles in the reboiler's shell-side and tube-side sections, to ensure that the minimum temperature driving force is positive and small. The clean-steam pressure is specified to avoid a temperature cross in the reboiler. The clean-steam side of the reboiler operates at nearly constant temperature and pressure.

The raw flashed steam enters the reboiler with a gas concentration determined by the conditions of the bulk-produced fluids and the designated flash conditions. As this vapor progressively condenses in the reboiler shell-side space, its dew point drops. For this study, the exit temperature of the condensing side sets the lower shell-side temperature limit, and the minimum temperature driving force of $1^{\circ} \mathrm{F}$ between the shell-side and tube-side conditions defines the clean-steam temperature and pressure. The average temperature driving force across the tube walls is much greater than $1^{\circ} \mathrm{F}$ because the flashed-steam dew point at the shell-side inlet is much higher than that of its counterpart vent gas at the dirty steam discharge. This factor defines the area of the heat transfer surface.

The second element in analyzing the reboiler is to determine the mass split of gases and steam between the effluent streams of vent gas and the product clean steam. In detailed design practice these material and energy balances are very calculation-intensive and subject to optimization for particular cases. The principal developer of the reboiler technology recommended some key assumptions to streamline the calculations (Coury 1999). These are based on a combination of empirical results from field tests of the reboiler process, and on the developer's experience analyzing the partitioning of gas/steam/condensate systems. The methods assume that $98 \%$ of the noncondensable gases flow to the vent gas stream, leaving the condensing side of the reboiler, and the vent gas comprises equal masses of steam and gases.

The dew point of the vent gas, minus the $1^{\circ} \mathrm{F}$ minimum driving force, defines the tube-side temperature. As the shell-side steam condenses, it absorbs the residual gases ( $2 \%$ of the inlet gas mass flow), and the condensate is flashed to the lower pressure of the clean-steam side of the reboiler. The tube-side condensate re-evaporates (reboils) partially by the adiabatic flash and partially by heat transfer from the condensing steam. 
The evaporating condensate is unable to absorb the entire latent heat duty of the condensing steam, and the reboiler heat duty must be balanced through an induced heat loss. This is done by adding a small amount of makeup water to the clean condensate. In actual operation, it is also necessary to discharge a small blowdown stream to control the buildup of salty brine entrained in the inlet raw steam. Using slightly more makeup water provides a convenient allowance for the blowdown.

The "clean" steam leaving the reboiler contains some ( $2 \%$ in this study) of the noncondensable gases from the raw flashed steam, so there is still a need for a vacuum system to evacuate the condensers. The gas-flow rates to the vacuum system will be greatly reduced, which reduces the vacuum system power demand. Compared to the raw geothermal steam with higher gas loadings, the cleaner steam leaving the reboiler will have a higher specific energy content, making the plant's main power turbine more productive per pound of throughput between its revised inlet and outlet conditions. And the cleaner steam will allow the existing condenser and vacuum system to draw down the turbine outlet pressure further, also increasing the turbine's productivity.

There are some other considerations with which to evaluate reboiler applications that could have significant site-specific impacts. A real-world design case for the reboiler should consider the possibility of increasing the production wellhead backpressure to raise the clean steam pressure and temperature. This could compensate for the enthalpy loss incurred flashing the clean condensate down to the reboiler discharge conditions. Depending on site-specific resource productivity, it may be possible to raise the backpressure on the production well system to raise steam enthalpy levels, while taking only slight reductions in flow rates per production well. Specifically, if a geothermal reservoir has a characteristic production curve (expressed as flow rate of brine and/or steam versus wellhead pressure) that is relatively flat in the range of plant design production rates, then a reboiler's pressure drop might be compensated.

On balance, this could enable a reboiler application to function at about the same turbine conditions as a straight-through production system, thereby avoiding potential costs for increasing resource production rates or for reengineering a turbine for a major change of steam conditions. These savings may offset the costs of a reboiler installation.

Detailed followup studies are needed to account for such variables in terms of the economics of optimized, fully integrated geothermal power systems. 


\section{Methods of Economic Analysis}

\subsection{System Approach}

This study analyzes the economics of gas-removal systems using the costs of their equipment, their calculated energy performance, and the resultant energy savings. In the spreadsheet, this analysis accounts for installing alternative gas-removal systems as retrofits to existing systems. The capital and operating costs of an integrated power plant are not involved in this analysis. The analysis could be converted to compare new-plant design alternatives by editing the spreadsheet to subtract the capital costs of a designated base-case system from the capital costs of an alternative.

Also, this is a technology screening approach, one which cannot suit the details of corporate accounting practices. It does provide a clear and practical first-cut estimate of the economics of gas-removal technologies. The user should carefully review the values of the financial parameters in this method. Those choices can be tailored to approximate the financial requirements of a specific facility or company. For example, the applicable price of electricity might not be the going market rate, but could be defined by contract performance incentives. In addition, the capital discount rate should be assigned according to a company's particular needs. There are several other financial parameters available for user input.

\subsection{Economic Figure of Merit}

The financial figure of merit estimates the net present values (NPV) of investments in alternative noncondensable gas-removal systems. The NPV method serves to rank the options. The NPV results are subject to the limitations of the user-defined input data on capital and operating costs, and the degree to which the model matches the accounting methods an owner would apply.

The economic figure of merit computes the net present value of each alternative gas-removal system as if it were a stand-alone operating unit. The base-case design is omitted from the NPV calculations because the context of these comparisons is to illustrate retrofit alternatives. Hence, the base-case design is a candidate to be replaced.

The economic differences between gas-removal technologies are assessed in terms of their capital costs, operating costs, and supplemental revenues estimated for the net power that they saved compared to the base-case system design. This is a pragmatic method of comparing system economics. As a realistic design and operating issue, such a retrofit may or may not actually be able to generate salable electricity from all of the steam saved by a more efficient gas-removal option, depending on whether the installed power system has the capacity to use more steam. Market demand or regulations would also play a role in this assessment.

Since the figure-of-merit results are proportional to plant capacity, the results can be scaled to other plant sizes, as long as capital and operating costs are either carefully ratioed or determined specifically for those options, too. The spreadsheet product of this study estimates capital costs for gas-removal systems based on data from quotes or studies of different power plant sizes, using the convention of the power-law proportionality method for ratios of capital costs versus capacity. The user can assign a discrete cost/capacity power factor for each technology. 


\subsection{NPV Financial Parameters}

The following parameters are applied in the net present-value calculations in the spreadsheet. These may be specified by the user to control the computations:

\author{
Annual Stream Factor \\ Analysis Term \\ Depreciation Term \\ Depreciation Method \\ Annual Capital Discount Rate \\ Annual General Inflation Rate \\ Annual Electricity Value Inflation \\ Electricity Contract Price \\ Operating and Maintenance Costs \\ Labor Load
}

O\&M Labor Rate

General Expenses

power

Salvage Value

costs

Annual Tax Rates
Power plant percent of time on-line

Time period of NPV analysis, 1 through 15 years

Time period for capturing depreciation, 1 through 12 years

Straight line (not user selectable)

Percent interest rate for discounted cash flow calculation

Percent general economic inflation (positive/negative)

Percent inflation/deflation of the value of electricity

Selling price, cents/kilowatt-hour, applied to electricity saved by improved gas-removal efficiency

Gas-removal system O\&M as percent of capital costs

A supplemental or alternative O\&M factor as equivalent workers per system

Cost of labor, fully burdened, for above Labor Load factor, \$/hour

Other costs, percent of the revenues from savings in parasitic

Depreciation basis of gas-removal system, as percent of capital

Percent of net income after deducting expenses and depreciation.

\subsection{Cost Data for Specific Gas-Removal Technologies}

Steam Jet Ejector Systems-This is the base-case design used as a reference from which to compute the energy savings and marginal costs of replacement for the alternative systems. There are no retrofit cases involving installation of steam jet ejectors, so there are no capital costs to apply for that consideration. Costs were obtained for a steam jet ejector vacuum system as a basis for competing ejector O\&M costs and to estimate installed costs for an eductor system by analogy (see below).

Three-Stage Turbocompressor Vacuum Systems-Preliminary capital costs for two sizes of turbocompressor units were obtained from the manufacturer of the technology tested at The Geysers geothermal field. Installation and maintenance costs are assumed as percentages of capital cost.

Hybrid Vacuum Systems - Capital costs for a hybrid system are based on adding a third-stage bank of vacuum units, using turbocompressors or LRVPs, to an existing two-stage ejector system. Manufacturer's capital costs were obtained for the units.

Biphase Eductor System - Capital costs are based on power-law extrapolations of the costs of a steam-jet ejector system. The sizing estimates take ratios of the volumes of motive brine flow to an eductor compared to the flow of motive steam to an ejector system. Prices for a steam-jet ejector system were obtained from industry contacts and are converted to an equivalent eductor system cost by analogy of flow area needed to handle the flashing brine flows. Industry contacts (Graham Corp. 1999) could not provide eductor cost estimates because that kind of application has not been commercialized. Therefore, this method of cost estimating has a higher uncertainty than, for example, the capital prices for the turbocompressor and reboiler units, which were provided by manufacturers. Operating and maintenance costs are assumed as a percentage of capital value of the system components. 
Reboiler System - Preliminary capital costs for a reboiler system have been obtained from two industry contacts (Coury, Swenson 1999). Operating and maintenance costs are assumed as a percentage of capital value of the system components. 


\section{Results}

This chapter discusses study results of the technical and economic figures of merit. The closing section interprets the results in pragmatic terms. These results are tabulated in detail in the spreadsheet printout in Appendix 2.

As a reminder, the following parameter values apply to the geothermal resource conditions:

- The "low-temperature" cases are for brine/steam mixtures entering the power plant flash tank at a temperature of $350^{\circ} \mathrm{F}$.

- The "high-temperature" cases are for a delivery temperature of $550^{\circ} \mathrm{F}$.

- All cases use a $15 \%$ quality (weight percent steam) at the inlet to the flash separator.

Figures 7 and 8 show the results of technical and economic performance analyses, respectively, of the low-temperature main case groups of this study. Figures 9 and 10 illustrate the corresponding performance for the high-temperature main cases. Each of these figures plots the figure of merit values on the charts' $y$-axes, versus the values of noncondensable gas concentrations in flashed steam on the $\mathrm{x}$ axes.

The spreadsheet product of this study calculates capital costs for gas-removal systems at the 50-MW power plant capacity. Because the figure-of-merit results are proportional to plant capacity, the results can be scaled to other plant sizes, as long as the capital and operating costs are appropriately ratioed from analogous units or determined specifically for those options.

The user should keep in mind a limitation concerning the gas-removal systems' estimated energy savings: the projected cost savings may not actually be capable of being captured in real-world plants. The estimated energy savings would theoretically be available at a matching level of gas-removal system efficiency. However, if the power plant systems are not capable of handling the "saved" steam to generate supplemental electricity, the dollar value of any saved steam has to be allocated elsewhere.

Table 5 lists the values of financial bases assigned to the cases presented here. Users can change the values of these variables in the spreadsheet to alter the present value calculations, independently of the technical input data.

Table 5. Variables for Financial Analyses

\begin{tabular}{|l|c|c|}
\multicolumn{1}{|c|}{ Variable } & Value & Units \\
\hline Contract price of (saved) electricity & $\$ 0.04$ & per kilowatt-hour \\
\hline Annual stream factor & $90 \%$ & plant online time \\
\hline Plant salvage value & $10 \%$ & of original cost \\
\hline Capital discount rate & $10 \%$ & per year \\
\hline General inflation rate & $2 \%$ & per year \\
\hline Electricity price inflation rate & $2 \%$ & per year \\
\hline Tax rate & $34 \%$ & of net income \\
\hline Term of the analysis & 10 & years \\
\hline Depreciation period & 5 & years \\
\hline Operations \& maintenance costs & $5 \%$ & of capital cost \\
\hline
\end{tabular}




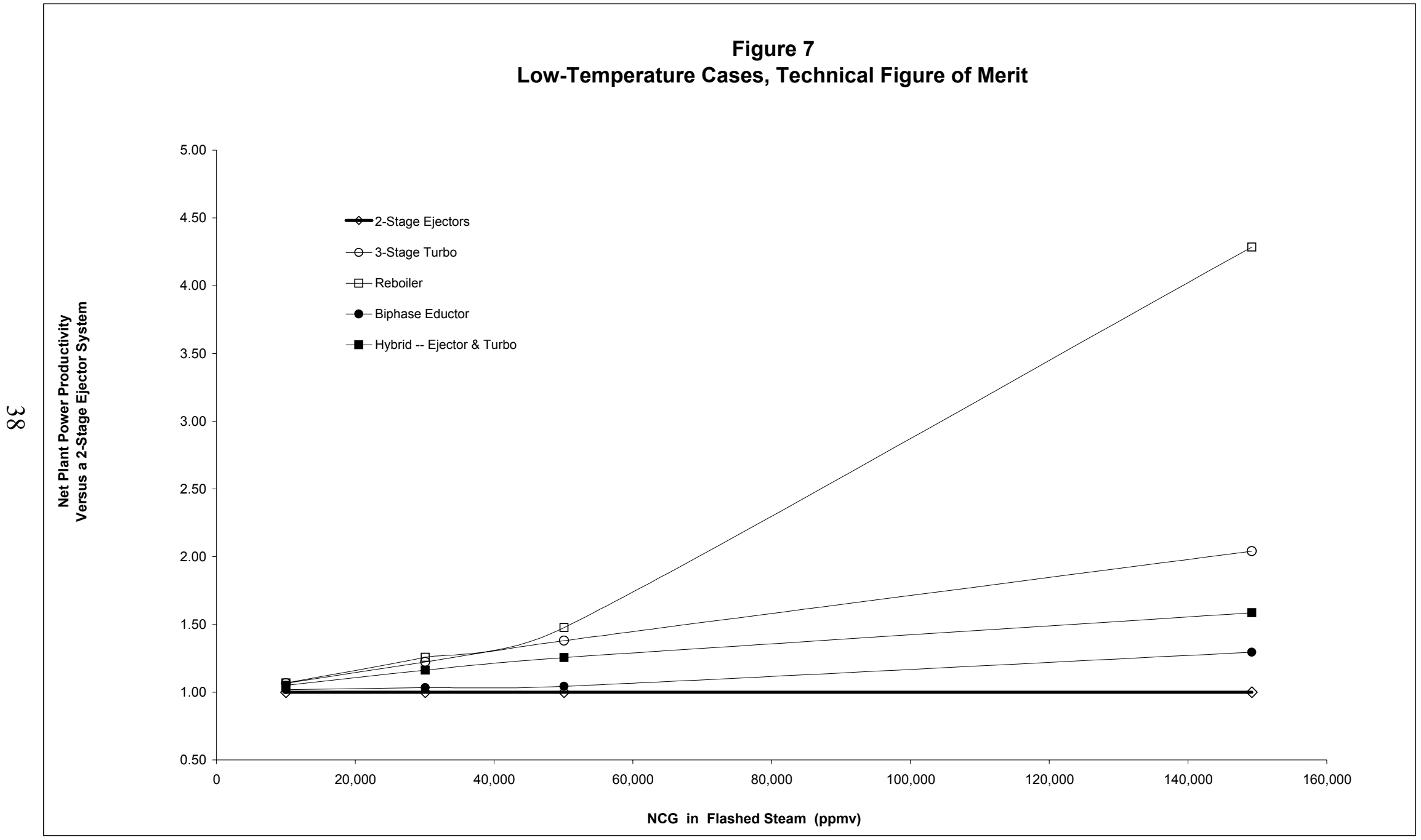




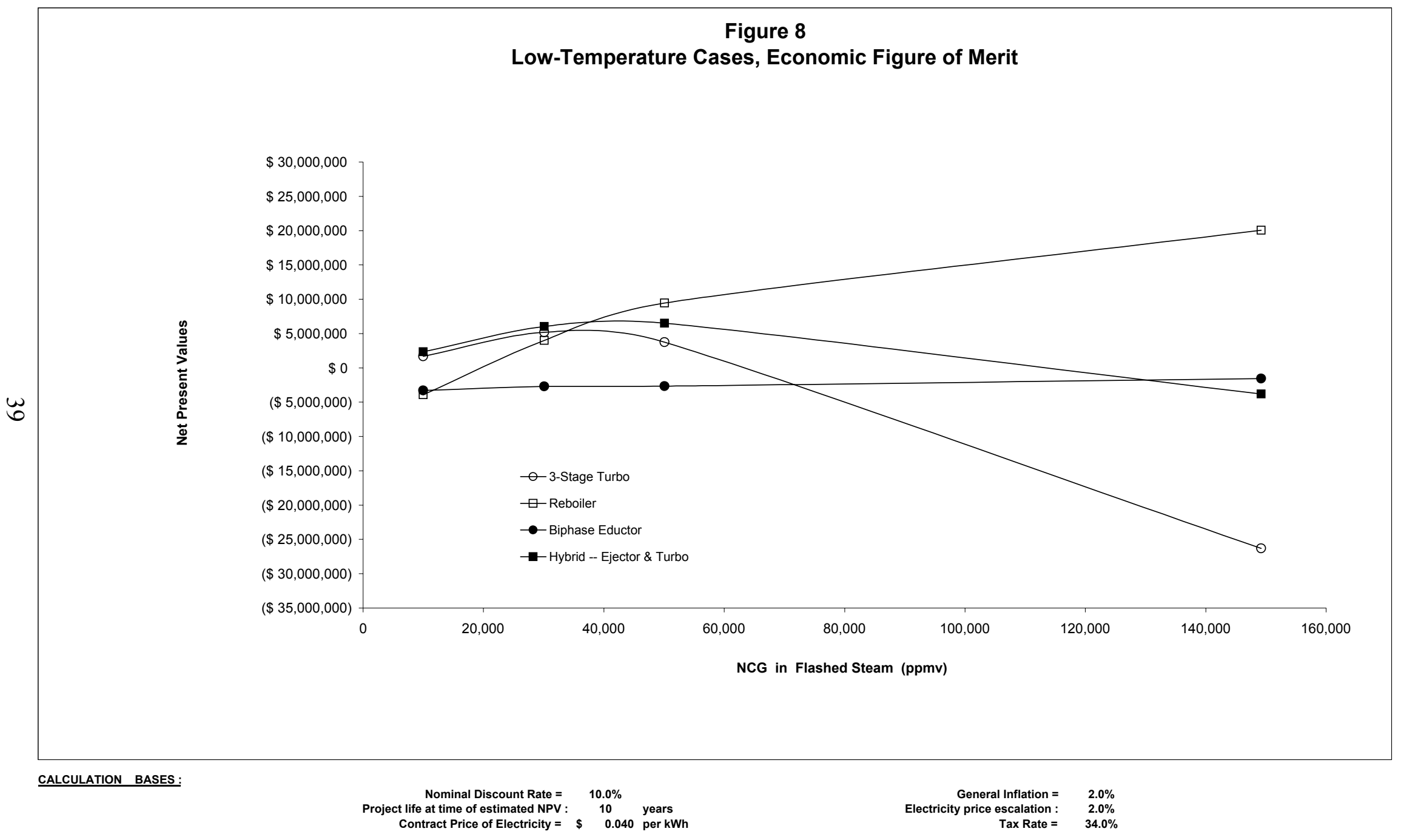




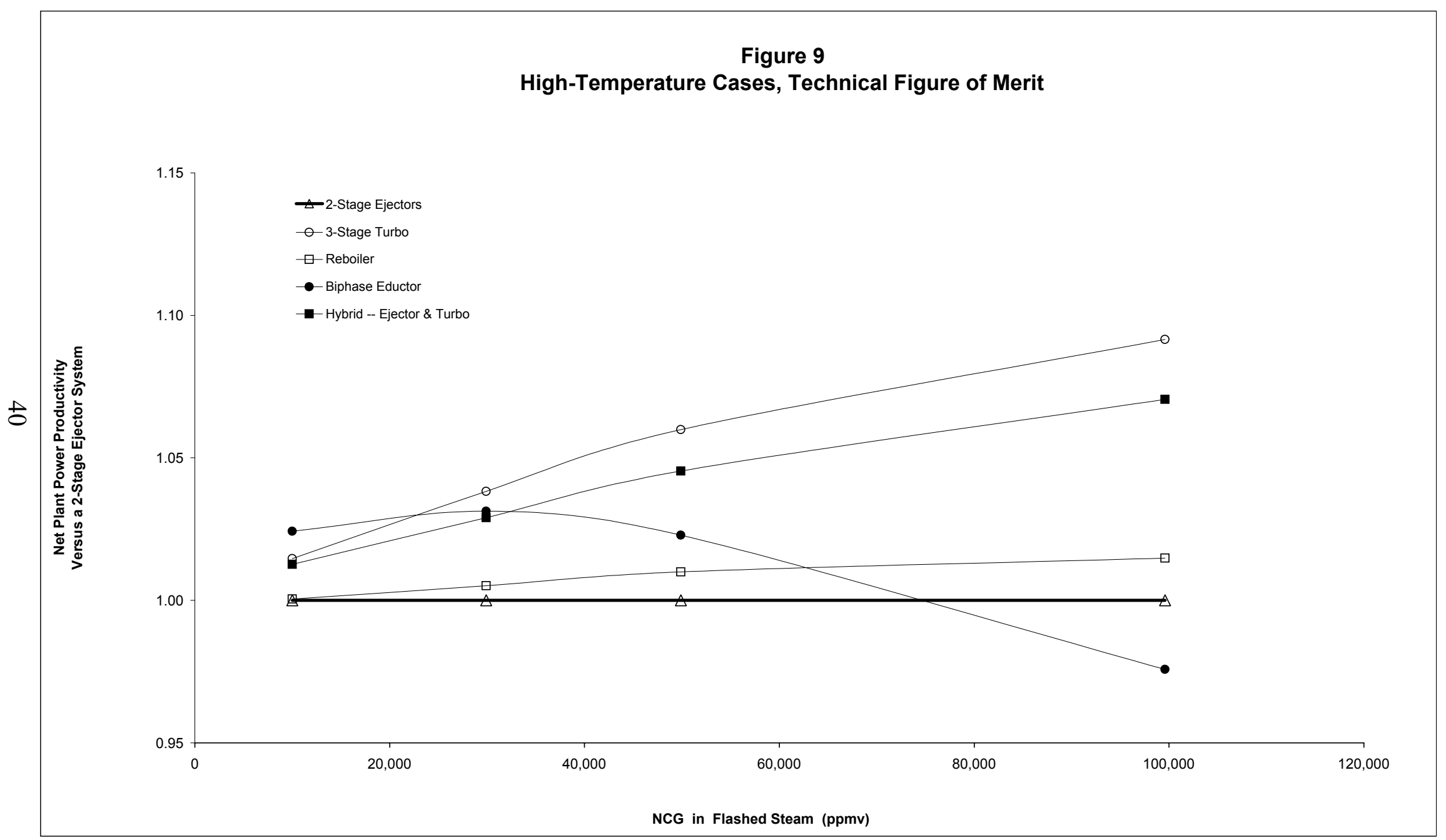




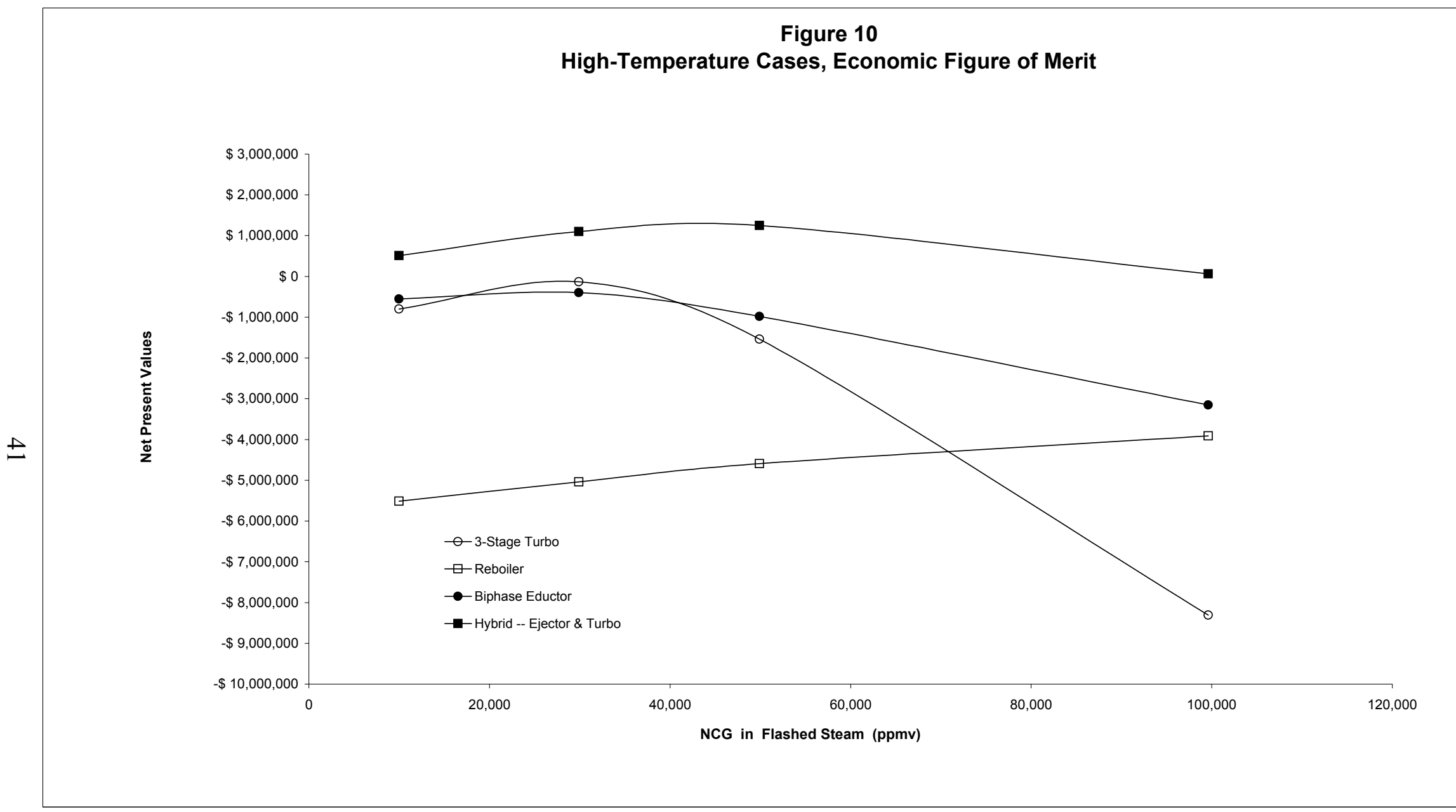

CALCULATION BASES

Nominal Discount Rate $=\quad 10.0 \%$ 


\subsection{Low-Temperature Cases}

Technical Performance-Figure 7 plots the values of the technical figure of merit for the gas-removal alternatives based on a brine/steam temperature of $350^{\circ} \mathrm{F}$ at the power plant flash inlet. The plots of figure of merit values for the gas-removal systems are symmetrical, showing differing degrees of improvement over the base-case configuration. By definition of the figure of merit, the base-case, twostage steam-jet ejector system would have a constant value of 1.0.

The best performers are the reboiler and the three-stage turbocompressor systems. At very high gas levels, the reboiler and three-stage turbocompressor systems' performance are such that they would yield, respectively, more than four times as much and about two times as much net salable electricity as a power plant relying on two-stage, steam-jet ejectors for gas-removal. This dramatic improvement reflects two considerations: the higher efficiencies of the gas-removal alternatives are compounded, and as the parasitic losses of the base-case mount, its small net power output is easily surpassed. However, if it were simply uneconomical to build and operate a conventional base-case type of power plant at the very high $(150,000 \mathrm{ppmv})$ gas levels, these dramatic calculated productivity improvements may not be of great practical value. Further economic evaluations at very high gas levels are recommended.

The hybrid case productivities rise gradually to the range of about $40 \%$ to $60 \%$ improvement over an ejector system. This option adds a third-stage turbocompressor or LRVP to a two-stage steam-jet ejector system. The gain in performance reflects a large improvement in the third-stage efficiency. With the underpinning of the first two stages of steam-jet ejectors consuming steam relatively heavily compared to the third stage, the parasitic power demand still grows sufficiently to limit the performance gains of the more efficient third-stage compressor. The two hybrid cases track each other fairly closely.

There is a slow gain in net power productivity for the biphase eductor across the full range of gas concentrations, reaching about a $20 \%$ improvement at very high gas levels. The reason for the low gains is that the spent brine intended to drive the eductors has only a small amount of residual energy to generate compression. Table 6 shows that the energy a pound of flashed steam can deliver in an ejector is about 19 times the energy that a pound of brine can deliver by flashing in an eductor. This means that the compression work available from one pound of steam would require 19 pounds of flashing brine to replace it. Considering the likely range of the ratio of brine flow to flashed-steam flow in geothermal power plants, this calculation also implies that eductors would have to be substantially supported by ongoing use of steam-jet ejectors to meet the gas-removal power load. The detailed mass and energy calculations tabulated in the spreadsheet bear this out.

The basis for this example is the flash conditions for geothermal fluids produced at $550^{\circ} \mathrm{F}$ and $15 \%$ quality; the stream was flashed to $334^{\circ} \mathrm{F}$ and 109 psia to produce steam. The motive steam and brine were flashed to 1.5 psia to drive their respective vacuum devices. These data are from a conventional Mollier chart, so the reader can readily confirm the comparison.

Economic Performance-The values of the economic figure of merit for low-temperature main-case groups are shown in Figure 8. The parameters used in these cases are summarized in Table 5. While the corresponding technical figures of merit showed parallel patterns, the economic figures show strong contrasts in trends and values. These results represent the net present value of cumulative energy savings available by switching from a conventional two-stage steam-jet ejector system for gas-removal to any of the alternatives.

At the end of 10 years after installation, the calculated net present value for a hybrid turbocompressor system is positive at gas levels up to about $100,000 \mathrm{ppmv}$, and up to nearly $140,000 \mathrm{ppmv}$ for the LRVP 
hybrid. The highest NPV values slightly exceed \$5 million, and they occur at gas levels between 30,000 and 50,000 ppmv.

The model shows that the NPV for a vacuum gas-removal system relying exclusively on three stages of turbocompressor units is positive after 10 years for noncondensable gas levels up to just over 60,000 ppmv. The peak NPV is about $\$ 3$ million to $\$ 4$ million in the range of gas concentrations of 30,000 to 50,000 ppmv.

Table 6. Recoverable Energy from Flashed Brine versus Flashed Steam

\begin{tabular}{|c|c|c|c|c|c|}
\hline \multirow[t]{2}{*}{ Stream } & \multirow{2}{*}{$\begin{array}{c}\text { T \& P } \\
\left({ }^{\circ} \mathrm{F} / \mathrm{psia}\right)\end{array}$} & \multicolumn{2}{|c|}{ Drive Fluid Specific Enthalpy } & \multicolumn{2}{|c|}{ Drive Fluid Power } \\
\hline & & $\begin{array}{l}\text { Inlet } \\
(\text { Btu/lb) }\end{array}$ & $\begin{array}{l}\text { Exhaust } \\
\text { (Btu/lb) }\end{array}$ & $\begin{array}{l}\text { Ideal Available } \\
\text { (Btu/lb) }\end{array}$ & $\begin{array}{c}\text { Actual Recoverable } \\
\text { (Btu/lb) }\end{array}$ \\
\hline & & & Isentropic & Isentropic & Nominal \\
\hline \multicolumn{6}{|c|}{ (1) Energy Available from Flashed Steam Driving a Jet Ejector at $23 \%$ Efficiency: } \\
\hline $\begin{array}{l}\text { Flashed } \\
\text { Steam }\end{array}$ & $334 / 109$ & 1112 & $\begin{array}{c}913 \\
\text { (via turbine) }\end{array}$ & 276 & 63 \\
\hline \multicolumn{6}{|c|}{ (2) Energy Available from Flashed Brine Driving a Biphase Eductor at $10 \%$ Efficiency: } \\
\hline Flashed Brine & $334 / 109$ & 305 & $\begin{array}{c}271 \\
\text { (via eductor) }\end{array}$ & 34 & 3.4 \\
\hline \multicolumn{5}{|c|}{ Ratio of Energy Recovery from Flashed Steam Versus the Underflow Brine: } & 19 \\
\hline
\end{tabular}

The reboiler NPV is negative after the 10-year term for gas levels below about 20,000 ppmv. Thereafter the NPV rises steadily, ending at roughly $\$ 20$ million on the graph. The reason this option continues to rise with gas levels is that the capital costs of the reboiler system do not have to increase in direct proportion to the gas levels. In contrast, for a simple vacuum system, the vacuum pump capacity must be added proportionally to match the growth of gas flow rates (though there may be some economies of scale for pumps to limit their cost growth).

For low-temperature resource conditions, the biphase eductor technology shows a slowly rising but negative net present value at all gas concentrations. This is based on a compression efficiency of $10 \%$ per stage. Because of the uncertainties about the potential efficiency of the eductor, the authors ran a supplemental performance calculation, doubling the assumed efficiency to an optimistic $20 \%$ for all stages. This doubles the recovery of parasitic power, but the financial simulation shows that the eductor would achieve a modest positive NPV at the 10-year milestone only for gas concentrations above about 110,000 ppmv.

\subsection{High-Temperature Cases}

Technical Performance-Figure 9 shows the technical figure of merit values for the alternative gasremoval technologies based on a brine/steam temperature of $550^{\circ} \mathrm{F}$ at the flash inlet. Except for the biphase eductor, the patterns are symmetrical, showing differing degrees of continuous improvement over the base-case configuration. By definition of the figure of merit, the base-case two-stage steam-jet ejector system would have a constant value of 1.0. 
The three-stage turbocompressor system and hybrid systems show the best gains in plant productivity across all gas concentrations. The two hybrid configurations track closely to each other at all gas levels. The biphase eductor system starts out with the highest productivity gain at 10,000 ppmv gas levels, showing a slight productivity improvement with initially increasing gas levels. But above a noncondensable gas concentration of about 30,000 ppmv, the eductor figure of merit ratio declines continuously and falls below 1.0 at about the 75,000 ppmv gas level, which means the biphase eductor system would consume more parasitic energy than a two-stage ejector system at high gas loadings.

In contrast to the low-temperature cases, the reboiler has fallen below all the other technologies in power productivity gains up to a gas concentration of just over 60,000 ppmv. Thereafter, the reboiler efficiency exceeds that of the biphase eductor, but shows markedly less improvement than the hybrid and three-stage turbocompressor cases.

The productivity gains for high-temperature cases are consistently less than seen in the low-temperature cases. This is because the high-temperature drive steam has much higher available energy values than the corresponding low-temperature flashed steam. Therefore, even for the low-efficiency steam jet ejectors, the demand for energy for gas-removal, as a function of plant capacity, is a smaller fraction of the net plant output in the high-temperature cases. Thus, the reductions in the parasitic energy demand gained through improved efficiency also appear as a smaller changes in net plant output.

This means that productivity gains are inherently harder to capture for high-temperature systems than for low-temperature units.

Economic Performance-As shown in Figure 10, the NPV results for the five alternative gas-removal systems at high temperature differ markedly from those for the low-temperature cases. The economic parameters used in these cases are summarized in Table 5.

The hybrid systems show the only positive NPV results. The hybrid NPV results trend upward to gas levels in the range of about 40,000 to $50,000 \mathrm{ppmv}$, then they taper off to low values at about 100,000 ppmv. The hybrid turbo system shows an advantage over the hybrid LRVP system, with nearly twice the NPV of the LRVP system at gas levels between 30,000 and 50,000 ppmv.

The NPV of the three-stage turbocompressor system is negative at all gas levels. It comes close to a zero value at a gas concentration of about 30,000 ppmv, but the NPV trends decline strongly outside the gas concentration range of about 20,000 to 40,000 ppmv.

The biphase eductor shows a negative NPV of roughly $-\$ 0.5$ million for gas levels up to about 40,000 ppmv, and then it declines continuously with increasing gas concentrations. As with the low-temperature cases, the biphase eductor's performance was also calculated at a $20 \%$ stage efficiency because of the uncertainties about this parameter. This gave NPV results of about $\$ 1$ million, $+/-30 \%$, for gas levels of about 10,000 to 40,000 ppmv. The eductor NPV trends downward starting at about 30,000 ppmv, and again goes negative slightly above a gas concentration of 50,000 ppmv. The reboiler has an NPV value of roughly $-\$ 5.5$ million at $10,000 \mathrm{ppmv}$, and the NPV trends continuously upward to a best value of about $\$ 4$ million at 100,000 ppmv.

The tendency for the vacuum gas-removal alternatives to have NPV results that peak and then trend negatively is caused by increasing equipment costs as the gas levels become very high, coupled with only modest improvements in productivity (or loss in productivity, in the biphase eductor's case) relative to the base-case system design. The reboiler starts with a high negative NPV because of its very low productivity gains at low gas concentrations. However, its NPV is able to trend upward because reboiler 
system capital and operating costs are less dependent on the gas loadings than are the costs of vacuum systems.

\subsection{Interpretation of Results}

Hybrid Ejector/Mechanical Pump Systems-For power plant systems taking steam from both high- and low-temperature geothermal resource systems, the hybrid gas-removal options look attractive in terms of NPV over a wide range of gas concentrations. This may offer a fiscally low-risk implementation "bridge" method to prove or disprove the long-term commercial viability of the turbocompressor. That should lead to reductions in the current estimated unit pricing, according to the manufacturer. That, in turn, could open the way to large-scale application and larger total costs savings by expanding the use of turbocompressors to further replace conventional steam jet ejectors.

For LRVPs, the NPV results also suggest a wide range of profitable applications. The results of this study do not show a strong enough difference in NPV values at low temperature cases to give either hybrid configuration a decisive advantage. Since LRVPs are widely applied in industry and their manufacturing costs have probably already seen the benefits of economies of scale, this technology deserves consideration.

Three-Stage Turbocompressor Systems - This configuration shows potentially attractive economic values for gas levels to roughly 50,000 ppmv for low-temperature geothermal sources. At higher gas loads, the capital costs grow quickly out of reach for reasonable recovery periods for the low-temperature cases. In the high-temperature cases, the installation costs consistently outweigh the revenue values of energy savings from the turbocompressor's higher efficiency. Note that the hybrid vacuum systems are always more cost effective than the all-turbocompressor system configuration.

Reboiler Systems-The reboiler system's NPV results are superior for low-temperature systems for all gas levels over about 40,000 ppmv. For high-temperature resources, the reboiler has a negative NPV at all gas levels unless other considerations take effect. Specifically, if the reboiler system could be implemented to reduce or eliminate the costs of gas emissions abatement, the resultant savings may markedly improve the apparent NPV calculation for a reboiler system. A reboiler process application might also eliminate the need for condensers to contain tube and tubesheet internals, which could enhance the economic appeal of the reboiler process in both low-temperature and high-temperature geothermal systems.

Biphase Eductor Systems-The design and cost bases for eductors used in this study are speculative. Virtually no industrial data are available for comparable flashing-fluid, high-capacity cases. The eductor concept is inherently limited because of the low work potential of the spent brine that is intended to drive the eductors. If the technical and economic assumptions of this study are reasonable, the biphase eductor concept would lose money in all applications.

In all but one case in this study, the hypothetical eductor applications would still require supplementary vacuum power. This accounts for the calculations that show the eductor technology yields only a small percentage gain in productivity compared to the base case design. What this means in economic terms is that the biphase eductor option for gas-removal gives little marginal energy recovery with which to pay the capital and operating costs for conversion.

On the other hand, if actual eductor efficiencies are found to be roughly double the $10 \%$ value used in this study, or if capital costs prove to be lower than estimated, then the eductor system might be profitable in a near- to mid-term time frame. It would then face economic competition from other gas-removal options, though. 


\section{Conclusions and Recommendations for Future Work}

\subsection{Conclusions}

Following is a summary of the advantages and disadvantages of the subject technologies for removing noncondensable gases from geothermal power plant systems. All of the gas-removal alternatives consume less parasitic energy than the base-case system configuration. Not all such conditions are economically favorable, however, as shown by the economic figure of merit results.

Steam Jet Ejector Vacuum System-The central purpose of this study was to compare the other gasremoval technologies to the performance and economics of conventional steam-jet ejector systems that dominate the vacuum driver selection in geothermal power plants. Ejectors have these advantages:

- Compared to rotary vacuum equipment, ejectors have no moving parts.

- They are simple to operate and maintain.

- Compensating for limited turndown ranges, they can be economically installed in banks so parallel units can be taken on-line or off-line to meet variable process demands.

- They are the vacuum drive of lowest capital cost.

The disadvantages of the steam-jet ejector are:

- Low efficiency, hence very high drive-steam consumption and high resource drawdown.

- Limited individual turndown ratio, which means that their consumption of motive steam cannot be regulated to save energy under conditions of low demand for vacuum power. To compensate, multiple units are needed in parallel installations.

Hybrid Ejector/Compressor Vacuum System-The hybrid vacuum system configuration is more cost effective than straight jet ejector systems over a wide range of process operating conditions.

The advantages of retrofitting a vacuum system of steam-jet ejectors to a hybrid system are:

- It can be implemented incrementally.

- It minimizes risk by retaining existing vacuum units for a base of reliability.

- It supports bringing replacement technology from developmental status to fully commercial status at the least cost of achieving that level of reliability.

- Two pragmatic considerations may favor this configuration for retrofits. If the hybrid components are compact, they can use the same piping as the ejectors they supplement or replace, with limited system modifications. In addition, if the existing system includes steam jet ejectors with intercondensers and after-condensers, the condensers might still fulfill the cooling and volume reduction duties for the turbocompressors.

The primary disadvantage of a stepwise conversion to a hybrid configuration is that it may defer capturing the full economic benefits of the replacement technology. This assumes that a hybrid component mix might evolve to full conversion to an alternative, higher-efficiency technology, eliminating steam-jet ejectors altogether.

Three-Stage Turbocompressor Vacuum System - On balance, the turbocompressor technology offers significant gains in efficiency compared to steam-jet ejector systems. If its savings in steam consumption could be converted to revenues by generating equivalent electrical power, the value would offer an attractive return on investment for certain combinations of resource conditions and financial variables. It 
can be concluded that for low-temperature resources with gas levels in geothermal steam of 10,000 to nearly $60,000 \mathrm{ppmv}$, this technology is worth close evaluation. For high-temperature resources, the capital costs and financial variables need to improve for a full conversion to turbocompressors to be profitable.

The advantages of the turbocompressor technology are:

- It offers a major improvement in energy efficiency compared to steam jet ejectors, and this greatly reduces the demand for steam to operate the vacuum system.

- It can be implemented incrementally.

- Two practical considerations favoring this equipment for retrofits are that the turbocompressors are comparatively compact, and they use the same motive steam source as steam-jet ejectors, but less of it because of their higher efficiency. With limited modifications, the turbocompressors could tie into existing feed/exhaust piping, and the existing inter-condensers and after-condensers should still fulfill the needed vapor cooling and volume reduction duties.

The disadvantages of the turbocompressor technology are its initial capital installation and maintenance costs compared to those for steam jet ejectors. Significantly, the number of compressor units grows unrealistically at very high gas loadings. This suggests the need to develop turbocompressors with larger capacities.

Biphase Eductor Vacuum System-The biphase eductor, still a conceptual application, is not profitable under the bases of this study. It is estimated to have its highest cost-effectiveness for geothermal steam sources with high temperatures and gas levels of about 10,000 to 40,000 ppmv. However, at the assumed mechanical efficiency of $10 \%$, it requires more optimistic values of financial variables for eductors to be profitable. This option cannot be applied to dry-steam geothermal resources because they produce little or no brine.

Biphase eductors might offer several advantages over steam jet ejectors to drive the power plant vacuum system:

- The biphase eductor would use spent geothermal brine, still at elevated pressure after being flashed, as a motive fluid to generate vacuum in the power train. Capturing energy by this option would free up some flashed steam, normally consumed by steam-jet ejectors, to generate electricity.

There are a number of unknowns associated with the performance, design, and durability of high-velocity nozzles in flashing geothermal brine service. Potential difficulties include:

- There are no design data on nozzle and diffuser sizing, efficiencies, range of operating stability, compression ratios, etc.

- One study by the Office of Saline Water, U.S. Bureau of Reclamation, showed empirical efficiencies were only matched by analytical projections on a limited basis.

- Compared to a power plant system using steam-jet ejectors, the efficiency gains estimated for an eductor vacuum system were slight. It would be necessary in most cases to run parallel vacuum systems to supplement the compression energy available from flashing brine. Calculations indicated the supplemental power demand would be a large fraction of a conventional vacuum-system power load.

- Erosion and corrosion are de facto concerns for geothermal fluid conditions. Eductors require high velocities to reach their maximum efficiencies, and the combination of conditions can be especially destructive.

- Scale formation is a general concern. 
Reboiler Process for Feed Steam Cleanup-If its estimated savings in steam consumption could be converted to revenues by generating electrical power, the savings could produce positive net present values for gas levels above 20,000 ppmv in low-temperature geothermal power systems.

The reboiler achieves a sharp separation of gases and steam, yielding a much cleaner steam phase for turbine feed, and a high-pressure, concentrated stream of the noncondensable gases. The reboiler process offers both immediate and potential advantages compared to relying on a steam-jet ejector vacuum system downstream of the primary condenser. A downstream vacuum system will still be needed to achieve an efficient steam power cycle, but the capacity of the system would be much smaller with the reboiler diverting most of the noncondensable gases away from the power train.

The immediate advantages of the reboiler process are:

- Vacuum equipment and secondary condensers of the plant vacuum system will be reduced in both size and energy demand in proportion to the reduction in gas content of the steam.

- The reboiler process uses simple, industrially proven equipment. The main component is a standard vertical-tube evaporator, and the reboiler design process is well defined.

- The concentrated vent gas from the reboiler can be either discharged to the atmosphere without the expense of compression or, if gas treatment is needed (for example, to abate hydrogen sulfide gas), the treatment process contact equipment can be integral multiples smaller than if the gases were treated at near-atmospheric pressure after being pumped out of the power plant vacuum/condenser system. Processes for gas abatement will likely see improved performance due to the increase in partial pressure of $\mathrm{H}_{2} \mathrm{~S}$ in the reboiler vent stream, as compared with the low-pressure gas exiting the vacuum system.

- The clean-steam phase produced by the reboiler yields higher specific energy output in the power turbine per pound of vapor because of the inherent higher enthalpy availability from clean steam compared to steam with percent levels of noncondensable gases. This partly compensates for the loss of steam energy due to the reboiler pressure drop.

- Because of the reduced gas concentration in the clean steam, the vacuum/condenser system will enable the power turbine to reach lower operating exhaust pressures. This improves the thermodynamic steam cycle, as another gain in the net yield of power per pound of steam; it helps to offset the lower turbine inlet pressure caused by the reboiler.

The disadvantages of the reboiler process are its economics:

- The main cost for the reboiler process is the capital cost of the reboiler infrastructure.

- The act of condensing and re-evaporating the raw geothermal steam incurs a pressure/temperature drop that costs the steam some energy potential. The balance will depend on local resource conditions.

- A variable portion of the flashed steam must be discarded with the noncondensable gases in the vent stream exiting the reboiler. The steam balances for gas-removal are reported in the spreadsheet.

The potential advantages of the reboiler process may also be economically superior to other gas-removal options in specific cases, depending on gas loadings and on whether gas emissions abatement (e.g., for $\mathrm{H}_{2} \mathrm{~S}$ ) is required. The economics of the potential advantages need to be quantified outside the scope of this study. They include these considerations:

- The noncondensable gases in geothermal steam are often dominated by acid gases, particularly carbon dioxide. Hydrogen sulfide and hydrogen chloride (hydrochloric acid) are also often present. The reboiler process greatly reduces the concentrations of these gases in the clean steam, and thereby 
shields the major power plant process systems and piping from exposure to corrosive vapor environments. Costs related to corrosivity of the geothermal steam are imbedded in initial capital costs and in ongoing maintenance costs, and may be reduced with the much cleaner steam.

- For geothermal resources that have relatively flat production curves (expressed as flow versus wellhead pressure), the reboiler feed conditions might be adjusted so that the reboiler could provide the same power availability as the raw flashed steam, but with lower steam mass flow rates. In this case, the geothermal resource production rates might actually be reduced by using the reboiler process.

- If gas abatement is required prior to atmospheric discharge, the high pressure and small volume of the vent gas stream offer an alternative: the vent gas could be injected back into the geothermal reservoir. This could be done as a stand-alone vapor stream or by blending the vent gas with spent brine on its way to a reinjection well site.

This potential advantage is very attractive but problematic to implement. If the reboiler process is economically justified based solely on reducing vacuum system parasitic power demand, and if emissions abatement could also be eliminated by resorting to gas reinjection, this scenario could dramatically shift the economics of the reboiler process. The avoided costs of an abatement system could be credited toward the costs of a reboiler system.

This alternative for gas reinjection has been considered and tried in the geothermal power industry. It has both economic appeal and potential risks. Noncondensable gases from the China Lake (California) geothermal development were initially recombined with spent brine and reinjected at one time in the site's operation, but the gas reinjection system was taken off line. At another geothermal site in the western United States, gas reinjection is working well as of this writing. (It eliminated the need for a treatment system to control gas emissions.)

However, there is a concern that this option to reinject the noncondensable gas stream may facilitate the gas phase making a rapid, short-circuit return back to a steam/brine production zone, thereby artificially degrading the produced steam quality. This would reduce the power-generating value of the steam by reducing its enthalpy and by creating a higher demand for parasitic power consumption in the power plant vacuum systems. Evaluating the potential for the short-circuit problem requires careful resource analysis.

\subsection{Recommendations for Future Work}

Sites with elevated gas levels in their flashed steam should be evaluated as candidates for adopting the alternative gas-removal methods, applying methodologies similar to the approach of this study in more detail. In the early stages of adopting any alternative gas-removal technology, retrofit systems should be approached by retaining existing vacuum system intact and operable, as a backup system for a transition period. It is common practice in process design to build in redundant capacity by adding spare units of selected components. This helps to minimize the impacts of production upsets due to mechanical failures in single units. By retaining existing gas-removal systems through a transition period, the new systems can be built more cost effectively with minimal redundancy; plant stream time can still be maximized by re-activating the old system, as needed. This is a temporary measure to delay the impact of changeover costs for new systems.

As a new system proves to be reliable, the old system could be mothballed or eliminated at minimum cost. Ultimately, as commercial experience is gained with new gas-removal methods, new plant designs may either drop steam-jet ejectors altogether, or use them as spares to cover a fraction of the installed new technology capacity. Experience with new technologies will provide data defining a prudent measure of system redundancy and plans for maintenance and repairs to optimize operating availability. 
The main recommendations for the gas-removal options are to seek opportunities to implement two systems in the near future: the hybrid vacuum system configurations and the reboiler process appear to support profitable conversions in time frames of 10 years or less. The estimates of this study show that their economics range from modest to strong justification for retrofitting steam-jet ejector systems, depending on several factors. The more important factors are:

- $\quad$ Equipment capital costs

- Capital discount rates

- Tax rates

- $\quad$ Operating and maintenance rates

- The value of saved energy

- Inflation rates

Hybrid Ejector/Compressor Vacuum Systems-The cost estimates of the turbocompressor technology reflect a limited manufacturing volume basis; nevertheless, the economic results of this study suggest its potentially profitable application in hybrid systems for low- and high-temperature resources at gas levels of 10,000 to nearly 100,000 ppmv. The appeal of the turbocompressor lies in its higher efficiency and compact size. The turbocompressor capital costs should shrink with growth in demand for the units. The hybrid vacuum system configuration offers a way to bootstrap the economics of the turbocompressor hardware by making phased additions of turbocompressors to plants. This is a way to gain experience while controlling risks, which are principally associated with limited though encouraging data on equipment durability.

Hybrid systems using LRVP units should also be assessed in competition with turbocompressors. The estimated performance and economics of both hybrids fall close together in most conditions, and more detailed economic evaluations are needed to finalize choices between the two options.

Reboiler Process for Feed Steam Cleanup-The risks of implementing the reboiler process are different from those of opting for a vacuum technology such as the turbocompressor. Future work to evaluate reboiler prospects will have to define the risk/reward balances in detail, using the following considerations. Unlike replacing components of the vacuum system with units of higher efficiency, the reboiler process is not suited to incremental implementation, at least not without a temporary, significant penalty to overall efficiency of power generation.

The reboiler process may lack application, in part, for want of clear and detailed assessments of the complete economic impacts of the process as a primary means of removing noncondensable gases. The results of this study suggest a reboiler process is worth considering for low-temperature power plants with gas levels in steam greater than about 20,000 to 30,000 ppmv.

The economic viability of the reboiler process may be highest for facilities that require gas abatement, for example, as applied to reduce $\mathrm{H}_{2} \mathrm{~S}$ emissions. This latter consideration is applicable to either improving the efficiency of a gas treatment process or to eliminating gas treatment in favor of gas reinjection. This possibility may also offer profitable conversion to reboiler systems in high-temperature power plant systems.

For most candidate sites, the evaluations of the reboiler process should be directed at making accurate economic models of capital investments and savings in operating costs. However, the option for using the reboiler process to facilitate reinjecting its high-pressure vent gases in order to avoid gas abatement costs requires an extra measure of caution. There can be a real risk of gas short-circuiting that could poison produced fluids. However, such a risk may be mitigated with improved geologic assessment. In 
addition, the savings available through the reboiler process may compensate for deeper or more remote reinjection wells.

Biphase Eductor Vacuum Systems-Data are needed to develop design models for eductor nozzles and diffusers, and to test the effects of high velocity, flashing flow, salts, and corrosive brines on materials of construction. For eductor applications to be economically attractive, the assumptions of this study have to be improved for both thermodynamic efficiency and capital costs.

For biphase eductor technology to progress in the geothermal power industry, the following evaluations are recommended. These tasks should be done serially, with cutoff decisions at any point where overwhelming negative results arise:

- Screening assessments of potential capital and maintenance costs and of technical factors to refine the assessment of performance and economic feasibility developed in this study.

- More extensive literature searches to assess the potential effects of velocities, temperature, and scaling tendencies on materials, especially for the eductor nozzles and in the injection wells and the geologic formations.

- Laboratory-scale testing to determine design ranges of compression efficiencies and operating stability, and material selection options for resistance to corrosion and erosion. Testing would address the key variables of brine compositions and properties, operating temperatures, fluid phase ratios and velocities, and pressure ratios.

- Lab-scale testing to quantify the parameters that present unmanageable risks or actual occurrence of scale formation.

The results of the preceding tasks should be analyzed in regard to site-specific conditions for possible applications with the best chances for success. Then, if the results are still encouraging, larger-scale testing and perhaps approval for field implementation could follow. The interpretation of results at the end of Chapter 6 gives an overview of the potential gains in economic performance of the eductor concept if the assumed efficiencies and estimated costs are improved.

Three-Stage Turbocompressor Vacuum System-In economic and practical terms, the turbocompressor has limited potential option for completely replacing steam-jet ejectors in geothermal power plants. As described above, using the turbocompressor in partial conversions to hybrid systems seems to provide higher economic returns. Turbocompressors might replace other mechanical vacuum equipment as well; however, that would depend on the difference in efficiencies and costs between the turbocompressor and a target unit. This study evaluated the turbocompressor only in terms of replacing low-efficiency steam jet ejectors.

Reviewers have noted that the implied capacities of any mechanical vacuum equipment to replace steam jet ejectors in first-stage power plant gas loads may be unrealistic, and that is a real concern. The authors of this study compiled three-stage turbocompressor arrays using the manufacturer's data on unit capacities, and we agree that at high gas loadings, the numbers of units needed to meet the mass flow demand do look unrealistic. Still, the economic analyses show some promise in spite of high unit costs. It will be up to the marketplace and manufacturers to determine if larger and more cost-effective turbocompressors can meet such demand. 


\section{Appendix 1 \\ Bibliography and Works Cited}

Bharathan, D.; Parent, Y.O.; Hassani, A.V. (1996). "Direct-Contact Condensers for Geothermal Applications: Analytical Model Description.” National Renewable Energy Laboratory: U.S. Department of Energy under Contract No. DE-AC36-83CH10093, Task No. GT613002. July.

Bloomster, C.H.; Fassbender, L.L. (1979). "The rule of second law analysis in geothermal economics," Energy, Vol. 5, No. 8-9, pp. 839-851. (1980). In: Second Law Analysis of Energy Devices and Processes, Cambel, A.B.; Cutler, D.W.; Heffernan, G.A.; Ghamarian, A., eds., Proc. of a Workshop, 14-16 August, 1979/Exergy, Geothermal economics//.

Bodvarsson, G.; Eggers, D.E. (1972). The exergy of thermal water. Geothermics, ITA, Vol. 1, No. 3, pp. 93-95. Exergy, Geothermal energy.

Bowlen, David. (1999). Personal communication. Swenson Industries. September.

Burgman, J.; Hattar, M.; Nichols, K.; Esaki, Y. (1996). Next Generation Geothermal Power Plants. Report EPRI/RP 3657-01. Pasadena, CA: C.E. Holt Co. February. Research supported in part by Office of Geothermal Technologies, U.S. Department of Energy.

Carroll, J.J.; Mather, A.E. (1993). "Fluid Phase Equilibria in the System Hydrogen Sulphide-Water at High Pressure." Application of an Extended Henry's Law. Chemical Engineering Technology, 16. pp. 200-205.

Carroll, J.J.; Slupsky, J.D.; Mather, A.E. (1991). "The Solubility of Carbon Dioxide in Water At Low Pressure." Journal of Physical and Chemical Reference Data. Vol. 20, No. 6, p. 1201.

Coury, G.E. 1999. Personal communication. July/August.

DiPippo, R. 1999. Personal communication. August.

DiPippo, R. (1980). Geothermal Energy As a Source of Electricity, A Worldwide Survey of the Design and Operation of Geothermal Power Plants. Brown University, U.S. Department of Energy, Contract No. AS02-76ET28320. January.

Dukler, A.E.; Elliott, L.C.; Farber, A.L. (1971). Distillation Plant Data Book. Office of Saline Water, Contract No. 14-01-0001-2099. January.

Ellis, A.J.; Mahon, W.A. (1977). J. Chemistry and Geothermal Systems. Academic Press.

Fernandez-Prini, R., Dooley, R.B. (1997). "Properties of Water and Steam." Release on the IAPWS Industrial Formulation 1997 for the Thermodynamic Properties of Water and Steam. EPRI. September.

Gong, M.; Wall, G. (1997). On Exergetics, Economics and Optimization of Technical Processes to Meet Environmental Conditions. Taies 97. Beijing, China. June 10-13.

Graham Manufacturing Company. (1998). VacWorks Software, Vacuum and Heat Transfer Equipment for Process, Power, Nuclear, Marine, and Commercial Industries. Version 1.01. April 10. 
EPRI. (1998). "Guideline on the Equilibrium Constant for the Distribution of Gaseous Solutes Between Steam and Water." Draft. September.

Joseph Kaye \& Company, Inc. (1970). "Multiple-Phase Ejectors." Office of Saline Water, Research and Development Progress Report No. 538. March. pp. 169-187.

Jung, Douglas. Personal communication. July.

Keenan, B.S.; Keyses, F.G.; Hill, P.G.; Moore, J.G. (1969). Steam Tables, Thermodynamic Properties of Water Including Vapor, Liquid, and Solid Phases. New York: John Wiley \& Sons.

Kestin, J.; DiPippo, R.; Khalifa, E.; Ryley, D. (1980). Sourcebook on the Production of Electricity from Geothermal Energy. Brown University, U.S. Department of Energy, Contract No. EY-76-S-4051.A002. March.

Khalifa, H.E.; Michaelides, E. (1978). The Effect of Noncondensable Gases on The Performance of Geothermal Steam Power Systems. DOE Contract No. EY-76-S-02-4051. November.

Kornhauser, Alan. (1999). Personal communication. Virginia Polytechnic Institute. August.

Levelt Senger, J.M.H., Dooley, B. (1992). "The International Association for the Properties of Water and Steam." Revised Supplementary Release on Saturation Properties of Ordinary Water Substances. St. Petersburg, Russia. September.

Olejniczak, J.S. (1997). SteamJet Ejector Software. JetSelect \& JetEval, System Overview and Background Information. Database Solutions.

Perry and Green. (1984). Perry's Chemical Engineering Handbook. 5th edition.

Price, R.M. (1998). RMP Lecture Notes. Reviewed at:

www/sunset.backbone.olemiss.edu/ cmprice/lectures/vacuum.html.

Power, R.B. (1994). Steam Jet Ejectors for the Process Industries. New York: McGraw Hill Book Company.

Reid, R.C.; Prausnitz, J.M.; Poling, B.E. (1987). The Properties of Gases and Liquid. 4th edition. McGraw Hill Book Company.

Ruck, D., R. Hagen. (1999). Personal communication. Graham Manufacturing Company, Inc. September.

Russel, H. (2000). Personal communication with Vooner Vacuum Pumps, Inc. March.

Siniougine, Dr. O.A. (DATE). Exergy Analysis of Geothermal Power Plants Efficiency. Laboratory for Renewable Sources of Energy, Department of Geography, Moscow State University, 119899. Vorobyevy Gori, Moscow, Russia.

Stermole, F.J.; Stermole, J.M. (1990). Economic Evaluation and Investment Decision Methods, Investment Evaluation Corporation. PUBLISHER? Golden. ISBN 1-878740-00-8.

Short, W.; Packey, D.J.; Holt, T. (1995). A Manual for the Economic Evaluation of Renewable Energy Technologies, Golden, Colorado: National Renewable Energy Laboratory. NREL/TP-462-5173. March. 
Wahl, Edward F. (1977). "Geothermal Energy Utilization." New York: John Wiley \& Sons.

Wall, G. (1998). Energetics. Preliminary Copy, Molinda.

Watanabe, K., Dooley, R.B. (1996). "The International Association for the Properties of Water and Steam." Release on the IAPWS Formulation 1995 for the Thermodynamic Properties of Ordinary Water Substances for General And Scientific Use. EPRI. September. 


\section{Appendix 2 \\ Spreadsheet Description and Printout}

The cases presented in this spreadsheet have a fixed basis of plant feed and process performance conditions: the conditions of the geothermal production geothermal fluids, and the model of the power plant systems. A downloadable version of the spreadsheet is located at http://www/nrel.gov/geothermal/geopublications.html.

The spreadsheet is meant to be used for generating any number of alternative case studies. The steps are straightforward: alternative values of geothermal fluid conditions and/or plant operation would be evaluated independently, and the resultant values of stream flows, gas levels, and power profiles can be processed in the spreadsheet.

The values of the figures of merit are graphed against the noncondensable gas concentrations to facilitate interpretation of performance and economics versus gas levels. Without generating additional power plant performance profiles, the economic figure of merit can be recalculated by assigning new values of the financial variables.

The worksheet numbers and contents are summarized as follows.

\section{Spreadsheet Layout and Organization}

\section{Project Organization and Case Data}

This group of worksheets deals with defining the bases for the process logic used in this study, and presents the results of thermo-chemical process calculations performed outside of this spreadsheet.

1.0 Title and Contents - This section presents the title page for the spreadsheet, showing the issue date and contractor information.

2.1 User's Guide- - This section leads the user to the sections of the spreadsheet via tool buttons that divert the user to specific presentations of the analyses of geothermal power plant and gas removal systems. The linked sections have return tool buttons to facilitate moving among related sections in a deliberate pattern.

2.2 Bases and Input-This section lists the calculation bases for the case studies, and also provides the user the option to change certain controlled variables to consider the effects of variations in key mechanical and economic parameters.

2.3 Flowsheets-This section provides two flowsheets that illustrate the overall model of a geothermal power plant, from which the cases for this study were isolated. Figure 4 is a simplified diagram showing the flow of material and energy in a typical geothermal power plant scheme, laying the basis for the model of this study that holds all parameters constant except for the demand for power to drive the noncondensable gas-removal systems.

The second diagram in this section illustrates a more complete process flowsheet for a power plant using two-stage steam jet ejectors to remove noncondensable gases from the condenser system. 
2.4 Calculation Logic-Two logic schematic drawings show the calculations profiles for the overall mass and energy balances of the power plant models, and for the balances of temperature, mass, and pressure in the plant condenser trains.

3.1 Main Case Summaries-These are the calculated results of the thermo-physical values for the power plant models at two combined fluid temperature levels and four values of noncondensable gas concentrations in the flashed geothermal steam. These values are input to the comparisons of technical and economic performance discussed below. This data must be calculated or estimated off line by the spreadsheet user to define the case profiles that the spreadsheet evaluates to compare technical performance and investment values.

3.2 Sensitivity Case Summaries-These are the calculated results of the thermo-physical values for the power plant models at site conditions that are alternatives to the main case conditions cited above. Specifically, these examine the effects of an elevated wet-bulb temperature, reduced steam-jet ejector efficiency, and a higher flash temperature for the high-temperature resource cases. These values are input to the comparisons of technical and economic performance discussed below.

\section{Performance Calculations and Comparisons}

Using the bases and detailed process calculations summarized above, following are the worksheets that depict the comparisons of the noncondensable gas removal technologies:

3.3 Figure of Merit Graphs - These graphs plot the figures of merit versus the noncondensable gas concentrations in the flashed-steam feed to the power turbine. The basis for the computations is a uniform nominal gross power plant output of 50 megawatts. Therefore, the technical figure of merit is scalable to other power plant capacities. The economic figure of merit can be adjusted off-line from the spreadsheet by the user, using appropriate capital cost factors to compensate for differing plant capacities.

3.3a. Alternative Figure of Merit Graphs - These graphs plot the same technical figures of merit, but the economic figure of merit is now expressed as net present values. The bases are as given for worksheet 3.3. Again, the technical figure of merit is scalable to other power plant capacities. The economic figure of merit can be adjusted by changing the financial bases defined in worksheet 2.2. However, the interpretation based on power plant capacity is narrowly defined per the 50-megawatt target.

3.4 Auxiliary Graphs - To help track continuity in the calculations, these simple graphs show the relationship between demand for drive steam in the noncondensable gas removal systems, versus the levels of gas in the flashed steam. The calculations result in rising and nearly straight-line relationships between the demand for motive steam and the gas levels in the turbine feed steam. The relationships between the operating curves for the technologies qualitatively match trends of efficiencies of the mechanical vacuum systems. The reboiler process shows the lowest vacuum steam demand because it removes about $98 \%$ of all gases upstream of the power train.

3.5 Issues - This is a chart to illustrate the qualitative differences between the optional gas removal technologies, and the areas of their relative strengths.

4.1 Ops (Operations) Details - This worksheet summarizes the case studies pertaining to the plant feed conditions, gross power output, and energy demand for removing the noncondensable gases. It concludes by expressing the effects of noncondensable gas-removal system efficiencies as the residual plant power available for sale. The power duty for the gas removal system is listed as a percent of the gross power plant capacity. 
4.2 Engineering Figure of Merit-The technical figure of merit is the ratio of residual power of any alternative gas removal technology to that of the base-case technology, which is a standard two-stage steam jet ejector system. The engineering figure of merit worksheet lists part of the case study operating data for continuity; it concludes with the values of power loss to gas removal, residual plant power output capacity, and the engineering figure of merit.

4.3 Economic Figure of Merit - In this worksheet, the economic figure of merit is the simple payback period, a rough estimate of the years to pay off the cost of installing an alternative gas-removal technology. It is the ratio of capital installation costs for each alternative gas-removal technology versus the net savings (or losses) realized by those technologies to remove noncondensable gases. The energy savings of each technology are the difference between its gas-removal power demands versus those of the base-case, two-stage steam-jet ejector system. The economic figure of merit worksheet also lists part of the case study operating data for continuity; it concludes with the values of power loss to gas removal, the capital and operating cost values, and the figure of merit values.

4.3a Alternative Economic Figure of Merit - This worksheet uses an alternative, more complex form of economic figure of merit that is the net present value of an investment in alternative gas-removal technology. The net present value is calculated using the estimated capital and operating costs for the alternative as the basis for installation and ongoing operations. Revenues are estimated as the contract value of energy saved (if available) by the new technology - this is the difference between total gasremoval power demands for the new technology versus those of the base-case, two-stage steam-jet ejector system. The economic figure of merit worksheet recapitulates part of the case study data; it concludes with the values of power loss to gas removal, the capital and operating cost values, and the figure of merit values.

As used in this edition of the spreadsheet, the net present value calculates the conversion cost for each technology as a retrofit to replace an already installed, operational gas-removal system. This approach calculates the benefit of investment in a new system while abandoning an old investment.

The benefit of using an alternative gas-removal system as original equipment in a new plant could be calculated, as well. This would entail evaluating the net present value of the marginal capital and operating costs - that is, the extra capital and operating costs of the alternative system - instead of using a base-case design. The basis for revenues to balance costs would still be the same as above: the difference between operating power demands for the two systems.

4.4 Cost Data-The project cost data package covers the capital cost estimates for the various technology options. Annual operating and maintenance costs are estimated as a percent of these capital costs. (This O\&M multiplier value is user-selectable in the "Bases and Input" worksheet.) These include costs for a steam-jet ejector system. This is the basis for scaling up to a fluid capacity for a biphase eductor system, and the basis for the operating and maintenance costs for the conventional ejector system. The O\&M costs for the ejector system are taken as a cost credit for the systems that replace or substantially reduce the role of the ejectors. Capital costs are also provided for the reboiler system and the turbocompressors. Capital and operating costs are also given for two types of abatement systems for abating hydrogen sulfide gas $\left(\mathrm{H}_{2} \mathrm{~S}\right)$. This provides a quantitative basis for the reader to consider the potential advantages of the reboiler system (i.e., it may serve to allow the abatement system to be eliminated if gas reinjection is viable for a particular geothermal resource).

\section{User Input to Spreadsheet}

The spreadsheet can be manipulated by the user to examine the effects of selected variables related to cost assumptions. The "Bases and Input" worksheet includes the following variables for user input: 
Annual stream factor-This is the percent of time that a facility is on line producing power. It applies globally to all cases. The user can set this variable to any value between 0.0 and 1.0. The effect directly determines how much power and revenue can be generated per calendar year. This study used a value of $90 \%$ on-line time.

O\&M Cost Factors-The user can specify operating and maintenance costs for each alternative gasremoval technology as a percent of that technology's capital costs of implementation. For the eight sets of main case study results presented in this study, the spreadsheet used a uniform O\&M multiplier of 5\%. It is clear that the very different gas-removal technologies are likely to be best represented by different values of the O\&M multiplier. However, for the purposes of this study, the differences in O\&M value would likely not have significant effects on the financial comparisons. In more detailed studies of closely rated alternatives, it would be important to refine the values of the O\&M factors.

Electricity Market Price-This is the effective value of energy saved by all of the noncondensable gasremoval options. For the case studies in this report, it is set at a value of 4 cents per kilowatt-hour. This treats the recovered energy as producing "found revenue," available at the costs of installation and operation of the alternative gas removal systems. No other indirect charges are assigned to the costs of replacement gas removal systems because the balance of the power system is in place. This is a subject that some will want to examine under the criteria of specific corporate economic policies for investments, taxes, etc., so the variable is made available for user input.

Capital Discount Factor-The user-defined rate of interest on money allocated to investment such as capital system installations.

General Inflation Factor-A cost inflation term that will apply to labor, materials, and other factors in operating and maintenance costs.

Electricity Price Inflation Factor-Because of the regulatory or contract influences on the value of electricity, it is assigned an inflation factor independent of the general inflation factor. It could be assigned a negative value, as needed.

Term of Analysis - The time frame for which the user wishes to calculate net present value. It can be between 1 through 15 years.

Term of Depreciation-The time frame during which depreciation will be captured for tax purposes. It can be between 1 through 12 years.

Annual Escalation Factor - Costs estimated in the past need to be escalated to present day values. For example, this study uses a 1993 study as one source of capital cost for the reboiler process. That value is escalated according to this escalation factor. The use may reset that factor according to differing judgements of market and regional factors. This study used an escalation factor of $3 \%$ per year.

Bare Equipment Installation Factor-Capital costs estimates were obtained for several key systems' major equipment items. Those values are ratioed up to represent the full installed equipment cost values using this installation factor as a multiplier. The user may change this value to suit judgements as to specific market and geographic conditions. The installation multipliers typically depend on system complexity, materials of construction, and other factors specific to a technology. In more detailed studies of closely rated alternatives, it would be important to refine the values of the installation factors. 
Power Law Exponential Factor-Capital cost estimates were obtained at capacity values differing from the nominal 50-megawatt gross power plant capacity. Capital cost estimates are frequently adjusted to alternate capacity bases by using the ratio of capacities (target value $\div$ estimated value) raised to a specified exponent. Such exponents depend on such factors as the type of technology, overall system complexity, materials selection, etc. This study used an exponent value of 0.6 . For more refined cost studies, this value should be set specifically for each technology.

The "Cost Data" worksheet allows the user to change the following variables:

Steam-Jet Ejector Capacities, Costs - The user can specify the drive steam rates and system costs for ejector systems to evacuate specified load as flow rates. These input values determine both the O\&M costs for the steam-jet ejector systems (used as a credit for the alternatives that substantially replace the ejector systems), and for estimating the capital costs of a hypothetical eductor system.

Biphase Eductor Design Parameters - The eductor technology has no firm engineering design bases for large-scale applications with flashing flow. This study uses a velocity analogy to estimate a ratio of the flow area of an eductor compared to that of a steam jet ejector. This area ratio is then used to extrapolate the eductor cost from that of an ejector systems sized specifically for this study.

To adjust this analogy, the user may change the specified values of steam and flashing brine velocities for the steam jet ejector and the eductor, respectively. The flashing brine vapor quality can be set, which in turn determines the fluid density calculation as part of the velocity consideration.

Turbocompressor Unit Costs - The user can specify unit prices for two sizes of turbocompressor units. Coupled with the installation cost multiplier, this gives the model complete control over the turbocompressor pricing. Secondly, the number of compressor units per vacuum system stage can be varied. The numbers shown in the spreadsheet printout were extrapolated from manufacturer's values for three gas flow rates well below the maximum values considered in this study.

Reboiler Equipment Costs-A bare-equipment cost was obtained from Swenson Process Equipment, Inc. The user may input alternative bare equipment costs and, as noted above, can change the installation cost ratio. A second cost estimate from a 1993 study is also incorporated in the basis, yielding an averaged capital cost estimate for this study.

$\underline{\mathrm{H}}_{2} \underline{\mathrm{S}}$ Treatment System Costs - This study illustrates that the reboiler process might enable $\mathrm{H}_{2} \mathrm{~S}$ gas abatement to be supplanted by gas separation and reinjection. The cost differences are not factored into the economic figure of merit, but the user may interpret the impact by considering the offsetting capital and $\mathrm{O} \& \mathrm{M}$ costs for $\mathrm{H}_{2} \mathrm{~S}$ abatement systems off-line from the spreadsheet. 


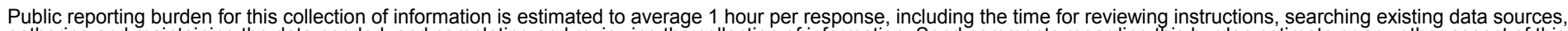

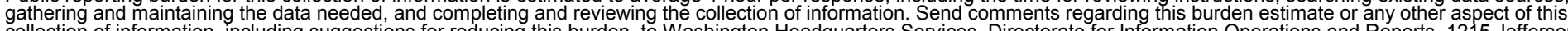

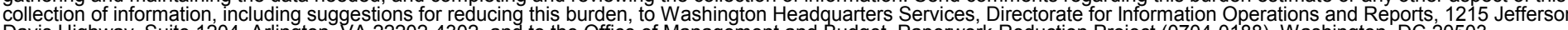
Davis Highway, Suite 1204, Arlington, VA 22202-4302, and to the Office of Management and Budget, Paperwork Reduction Project (0704-0188), Washington, DC 20503.
1. AGENCY USE ONLY (Leave blank)
2. REPORT DATE
3. REPORT TYPE AND DATES COVERED
June 2000
Subcontract Report: April 1999 - March 2000

4. TITLE AND SUBTITLE

Comparative Analysis of Alternative Means for Removing Noncondensable Gases from

Flashed-Steam Geothermal Power Plants
5. FUNDING NUMBERS

T: GT91.1006

C: AXG-9-29432-01

6. AUTHOR(S)

Martin Vorum, P.E.; Eugene A. Fritzler, P.E.

7. PERFORMING ORGANIZATION NAME(S) AND ADDRESS(ES)

Subcontractors

8. PERFORMING ORGANIZATION REPORT NUMBER

9. SPONSORING/MONITORING AGENCY NAME(S) AND ADDRESS(ES)

National Renewable Energy Laboratory

1617 Cole Blvd.

Golden, CO 80401-3393

10. SPONSORING/MONITORING AGENCY REPORT NUMBER

NREL/SR-550-28329

11. SUPPLEMENTARY NOTES

NREL Technical Monitor: Chuck Kutscher

12a. DISTRIBUTION/AVAILABILITY STATEMENT

National Technical Information Service

12b. DISTRIBUTION CODE

U.S. Department of Commerce

5285 Port Royal Road

Springfield, VA 22161

13. ABSTRACT (Maximum 200 words)

This is a final report on a screening study to compare six methods of removing noncondensable gases from direct-use geothermal steam power plants. This report defines the study methodologies and compares the performance and economics of selected gas-removal systems. Recommendations are presented for follow-up investigations and implementation of some of the technologies discussed. The specific gas-removal methods include five vacuum system configurations using the conventional approach of evacuating gas/vapor mixtures from the power plant condenser system and a system for physical separation of steam and gases upstream of the power turbine. The study focused on flashed-steam applications, but the results apply equally well to flashed-steam and dry-steam geothermal power plant configurations. Two gas-removal options appear to offer profitable economic potential. The hybrid vacuum system configurations and the reboiler process yield positive net present value results over wide-ranging gas concentrations. The hybrid options look favorable for both low-temperature and high-temperature resource applications. The reboiler looks profitable for low-temperature resource applications for gas levels above about 20,000 parts per million by volume. A vacuum system configuration using a three-stage turbocompressor battery may be profitable for low-temperature resources, but results show that the hybrid system is more profitable. The biphase eductor alternative cannot be recommended for commercialization at this time.

14. SUBJECT TERMS

geothermal, power plants, flashed-steam, noncondensable gases.
15. NUMBER OF PAGES

16. PRICE CODE

20. LIMITATION OF ABSTRACT OF THIS PAGE Unclassified
19. SECURITY CLASSIFICATION OF ABSTRACT Unclassified
UL 